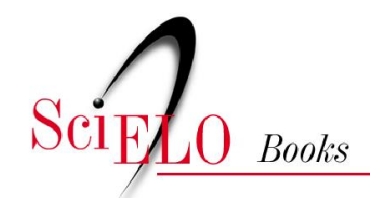

(1)

\title{
O percurso da Pesquisa e da Extensão na FAU-Mackenzie
}

\author{
Wilson Florio \\ Angélica Tanus Benatti Alvim \\ Eunice Helena Sguizzardi Abascal \\ Pérola Felipette Brocaneli
}

\section{SciELO Books / SciELO Livros / SciELO Libros}

FLORIO, W., et al. O percurso da Pesquisa e da Extensão na FAU-Mackenzie. In: ALVIM, ATB., ABASCAL, EHS., and ABRUNHOSA, EC., orgs. Arquitetura Mackenzie 100 anos FAU-Mackenzie 70 anos: pionerismo e atualidade [online]. São Paulo: Editora Mackenzie, 2017, pp. 268-298. ISBN 978-85-8293-726-6. Available from: doi: 10.7476/9788582937266. Also available in ePUB from: http://books.scielo.org/id/xrrzx/epub/alvim-9788582937266.epub.

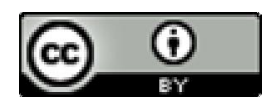

All the contents of this work, except where otherwise noted, is licensed under a Creative Commons Attribution $\underline{4.0 \text { International license. }}$

Todo o conteúdo deste trabalho, exceto quando houver ressalva, é publicado sob a licença Creative Commons Atribição 4.0.

Todo el contenido de esta obra, excepto donde se indique lo contrario, está bajo licencia de la licencia Creative Commons Reconocimento 4.0 . 
PROTAGONISMO DOCENTE E ESTUDANTIL:

PESQUISA E EXTENSÃO NA CONTEMPORANEIDADE E DESAFIOS FUTUROS

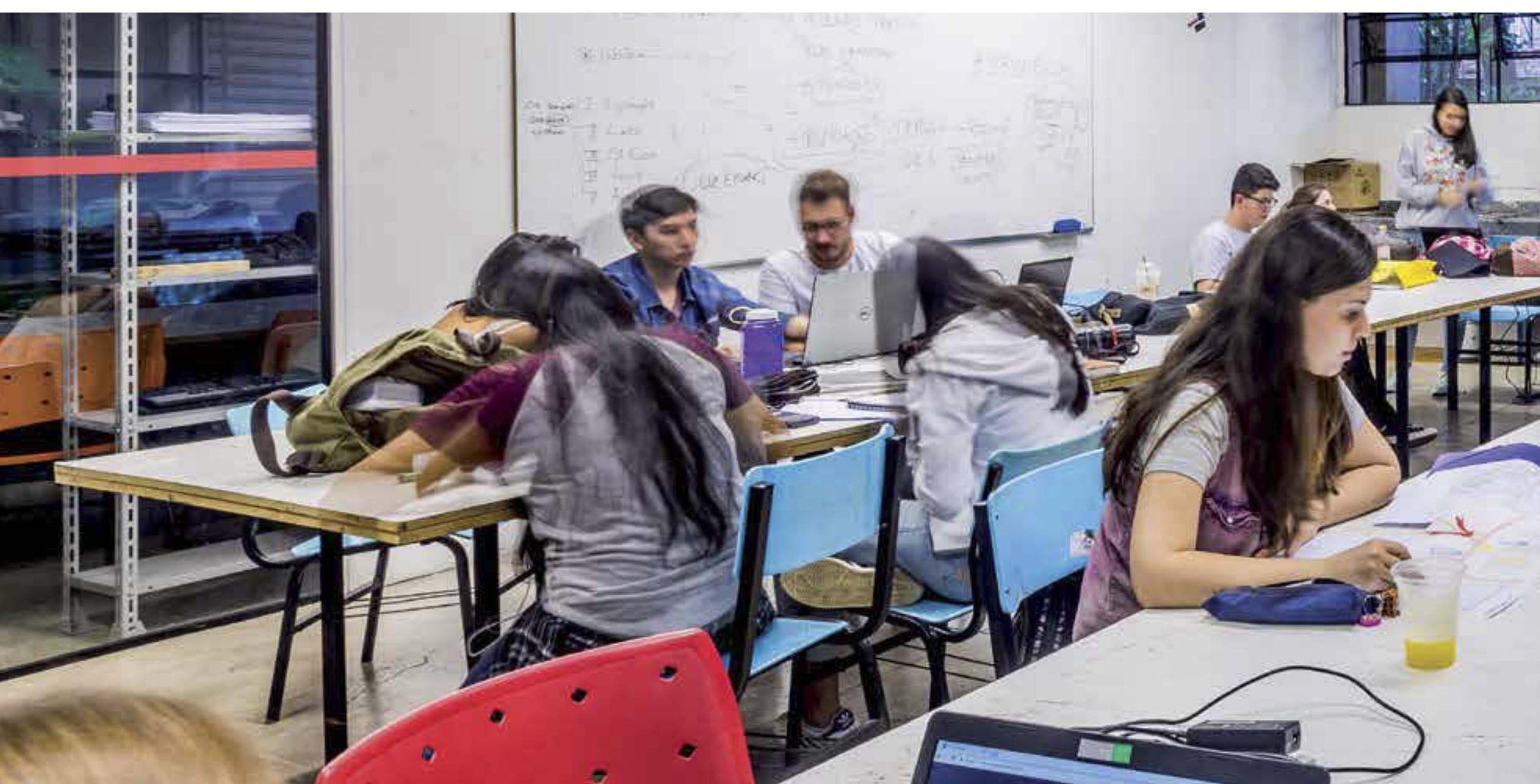




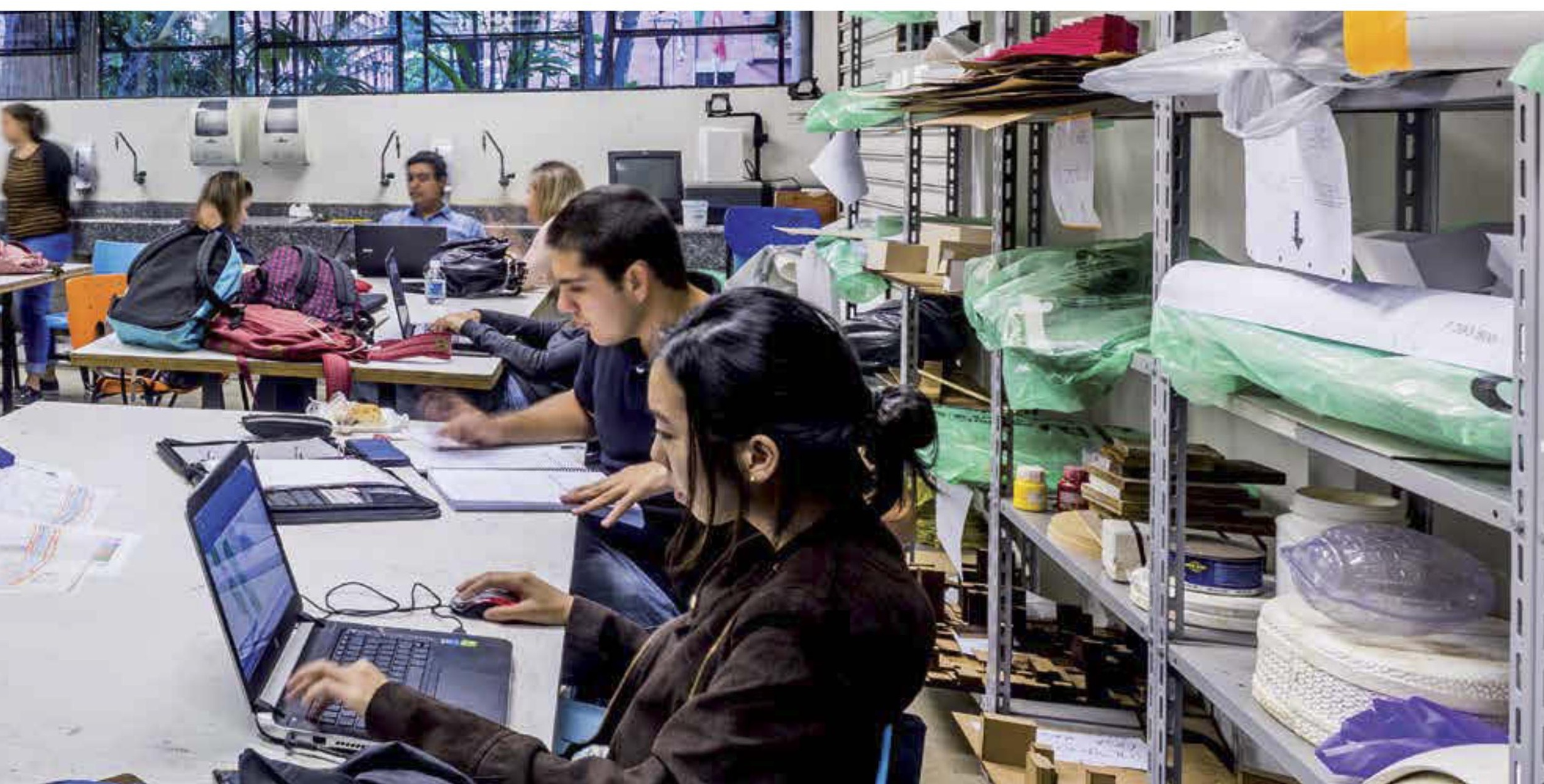


Mackenzie Day, setembro de 2016.

Evento de divulgação e apresentação

dos Cursos de Arquitetura e Urbanismo

e de Design à comunidade externa. $\mathrm{N}$

foto, oficinas e atividades ofertadas e

orientadas por professores e funcionários

da FAU-Mackenzie.

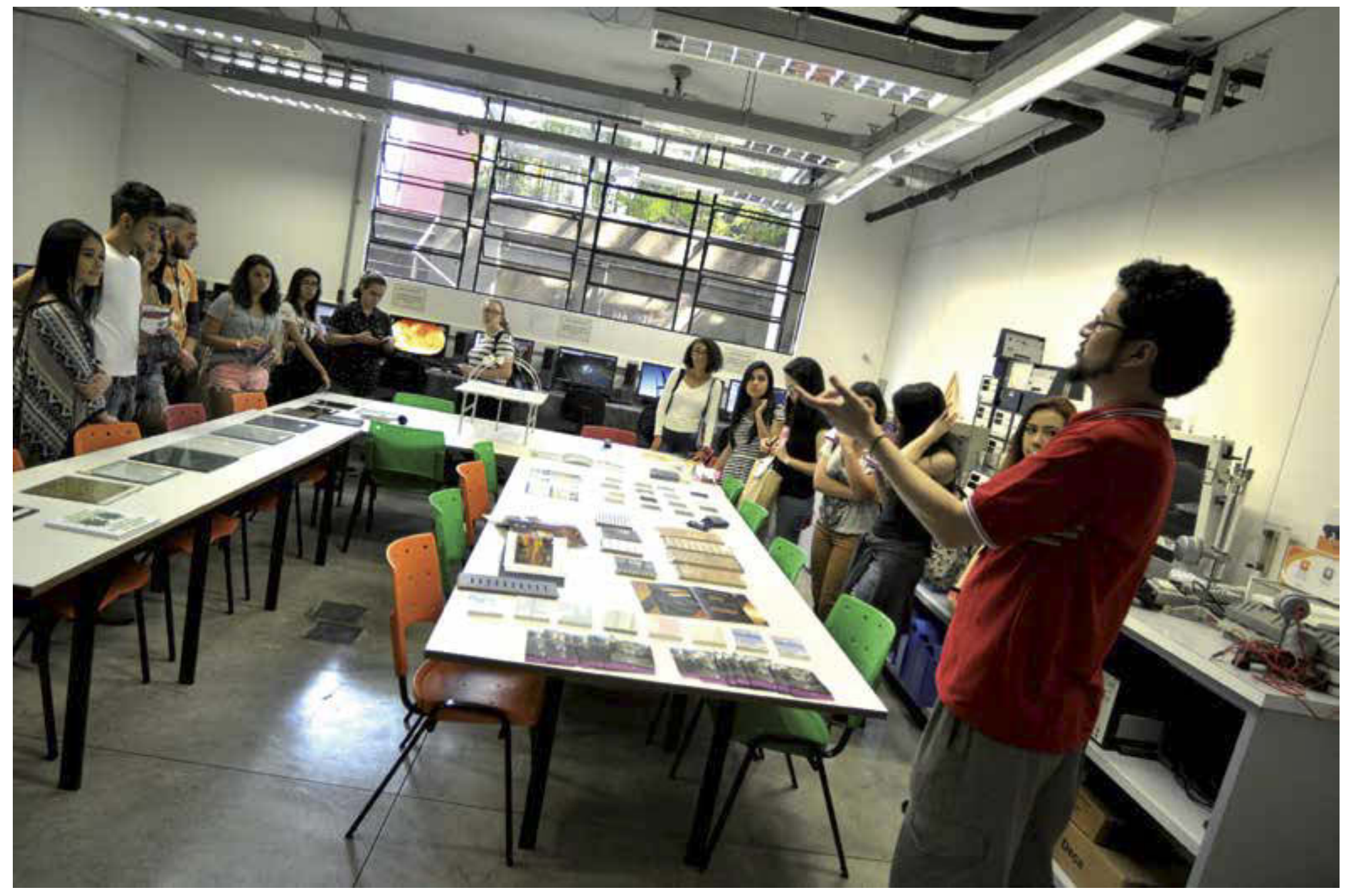




\section{O percurso da Pesquisa e da Extensão na FAU-Mackenzie}

Wilson Florio, Angélica Tanus Benatti Alvim, Eunice Helena Sguizzardi Abascal,

Pérola Felipette Brocaneli

Entre as escolas de maior tradição no país, a FAU-Mackenzie, criada em 1947, é reconhecida por sua excelência no ensino de Projeto, transmitindo uma gama de conhecimentos sobre a produção do espaço em suas diversas escalas. A Pesquisa e a Extensão na FAU-Mackenzie são atividades recentes. Durante 15 anos, com a criação da Pós-Graduação Stricto Sensu na década de 1990, a Pesquisa esteve predominantemente ligada a esse nível de formação.

No início dos anos 2000, a aprovação pela Comissão de Aperfeiçoamento de Pessoal de Nível Superior (Capes) ${ }^{1}$ do Programa de Pós-Graduação, com Mestrado Acadêmico, permitiu a ampliação das atividades de Pesquisa, iniciando um percurso integrado. A elaboração do Projeto Político-Pedagógico da FAU-Mackenzie ao longo de 2002, sob o estímulo das Diretrizes Curriculares Nacionais de Arquitetura e Urbanismo, teve como objetivo delinear instrumentos para uma reforma do processo de ensino-aprendizagem, para torná-lo integrado à Pesquisa e à Extensão, e irrigado pela produção de conhecimentos no âmbito de grupos e projetos de pesquisa.

A reforma universitária institucional de $2005^{2}$ abriu oportunidade para considerar a Pesquisa atividade fundamental à produção de conhecimento, indissociável do Ensino e da Extensão em seus diversos níveis, tendo a Pós-Graduação Stricto Sensu estreitado seus vínculos com as Unidades Acadêmicas. Ao transformar a estrutura da Universidade, conferiu-se à Pesquisa papel seminal na produção e difusão de conhecimento nos cursos, evitando a fragmentação do ensino e a segmentação disciplinar.

Em 2004, criaram-se os primeiros Grupos de Pesquisa da FAU-Mackenzie, vinculados ao Conselho Nacional de Desenvolvimento Científico e Tecnológico (CNPq), órgão ligado ao Ministério da Ciência e Tecnologia. Os grupos logo foram definidos como unidades fundamentais de produção de conhecimento e interlocução de pesquisadores. A Extensão foi sendo construída em paralelo, muitas vezes articulada às pesquisas, e em outras ocasiões derivada de iniciativas isoladas (mas não menos importantes) de professores e alunos.

Outros fatos decorrentes da reforma universitária foram fundamentais ao fortalecimento da Pesquisa e da Extensão: (i) em 2005, a incorporação da Pós-Graduação Stricto Sensu à Unidade e a criação da Coordenadoria de Pesquisa e Extensão (Cepex); (ii) em 2006, a incorporação do Curso de Design e a aprovação do Curso de Doutorado. Tais avanços permitiram ampliar as atividades de Pesquisa e Extensão, articular os cursos de
1. Órgão do governo federal incumbido de regrar a Pós-Graduação Stricto Sensu no país.

2. Nos anos 2000, a Universidade Mackenzie extinguiu a estrutura departamental vigente desde a década de 1970. Após a dissolução dos departamentos, as unidades universitárias passaram por uma reformulação para atender às Diretrizes Curriculares Nacionais, conforme a Resolução CNE/CES 06/2006. 


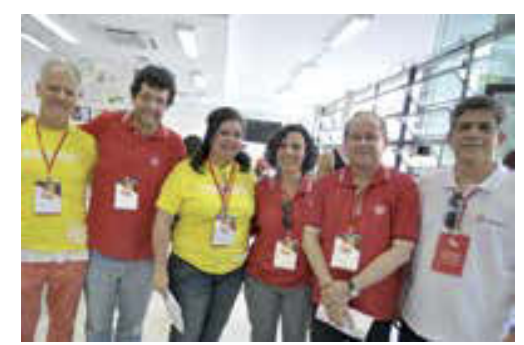

Mackenzie Day, setembro de 2016. Evento de divulgação e apresentação dos Cursos de Arquitetura e Urbanismo e de Design à comunidade externa. $\mathrm{Na}$ foto, da esquerda para a direita, Profs. Mauro Claro (Curso de Design); Lucas Fehr (Coordenador do Curso de Arquitetura e Urbanismo); Nara Martins (Curso de Design); Angélica Tanus Benatti Alvim (Diretora da FAU-Mackenzie); Reitor da UPM Benedito Guimarães Aguiar Neto, Vice-Reitor da UPM Marco Tullio de Castro Vasconcelos.

3. Desde 2006, as Coordenações de Pesquisa e Extensão vêm passando por transformações na Universidade Presbiteriana Mackenzie (UPM). Ora estão a cargo de uma coordenação, ora se desdobram em duas coordenações. Em julho de 2016, a UPM redefiniu nova estrutura das coordenações das Unidades Acadêmicas que propiciaram melhor desempenho de algumas áreas: a Coordenação de Pesquisa foi substituída pela Coordenação de Trabalho de Conclusão de Curso e de Pesquisa; a Coordenação de Atividades Complementares pela Coordenação de Atividades Complementares e Extensão; a Coordenação de Estágios pela Coordenação de Estágios e Protagonismo Estudantil. Nesse período, as Coordenações de Trabalho Final de Graduação e Pesquisa e de Atividades Complementares e Extensão da FAU ganharam dois coordenadores adjuntos, visando distribuir melhor o trabalho e as responsabilidades dessas duas importantes áreas.
Graduação em Arquitetura e Urbanismo e Design, envolver o Programa de Pós-Graduação Stricto Sensu com as atividades da Faculdade e implementar um rol de Cursos em nível de educação continuada. ${ }^{3}$

Data de 2005 a criação do Fórum de Pesquisa FAU-Mackenzie, idealizado a princípio para difundir a produção científico-acadêmica de professores e alunos e reforçar a cultura de Pesquisa nos níveis de Graduação e Pós-Graduação. O evento se estendeu a partir de 2008 à comunidade acadêmica nacional.

Nesse período, empreendeu-se reestruturação e aprofundamento das linhas de pesquisa existentes e dos Grupos de Pesquisa, e deu-se continuidade ao desenvolvimento de projetos de pesquisa, agora envolvendo docentes, discentes e pesquisadores, da Graduação à Pós-Graduação, além de participantes de outras instituições. No âmbito da Pós-Graduação, buscou-se o aprimoramento de disciplinas com novas propostas e novo elenco de optativas, além de disciplinas e atividades obrigatórias específicas do Doutorado.

\section{Pesquisa e Extensão em Arquitetura e Urbanismo}

Em Arquitetura e Urbanismo, a Pesquisa e a Extensão se tornaram atividades indissociáveis do ensino-aprendizado, o que justifica a realização de pesquisas exploratórias, elaboração de métodos e abordagens científico-acadêmicas em Arquitetura, Urbanismo e Design, para estimular a produção de conhecimento como parte da dinâmica de ensinar e aprender.

Latour (2011) define duas modalidades de pesquisa: a positiva - sentenças que afastam o enunciado de suas condições de produção; e a negativa - sentenças que levam o enunciado na direção de suas condições de produção. Ao aplicar essas proposições à pesquisa em Projeto de Arquitetura e Urbanismo, pode-se dizer que em geral comparecem as duas modalidades. Quando o pesquisador investiga a produção de artefatos como croqui de concepção, opera na modalidade negativa, da mesma forma ao produzir ideias e conceitos que norteiam as decisões arquitetônicas. No entanto, quando o pesquisador estuda o projeto acabado, opera na modalidade positiva, investigando as condições de produção do artefato, no contexto social e histórico-cultural.

O exame atento dos estágios iniciais de elaboração dos fatos, no processo de projeto, é no mínimo instigante, uma vez que o pesquisador se vê obrigado a enfrentar o desafio de interpretar as decisões e os caminhos trilhados pelo arquiteto no momento em que as ideias não estavam claras, e havia muitas possibilidades ainda abertas para explorar, constituindo-se em importante campo de pesquisa. 
Assim, ao mesmo tempo que os problemas relativos à abordagem científica parecem se tornar mais complexos, observa-se crescente elaboração, da parte dos arquitetos, da produção teórica, cujos instrumentos múltiplos e interlocuções definem um pluralismo de abordagens, o que dificulta qualquer chance de uma única e definitiva teoria. Esse pluralismo também é característica da produção arquitetônica recente. Na prática, o projeto devolve conceitos à teoria, permitindo que esta se enriqueça, confirmando-a ou negando-a. E de nada adiantará se o discurso teórico não se debruçar sobre o processo de projeto e o projeto em si, dessa maneira renovando e desafiando os conceitos e sua legitimação no âmbito da forma, da utilidade e dos procedimentos (ALVIM; ABASCAL, 2012).

Múltiplas possibilidades conceituais, formais e tecnológicas - posturas arquitetônicas (MONTANER, 2003) - ampliam os critérios de crítica e julgamento de excelência. É nesse espaço plural que a produção acadêmica, compromissada com o ensino e a profissão, propicia reflexão que aproxima teoria e prática, contribuindo para enunciar os parâmetros de valor da Arquitetura e do Urbanismo, por um lado, e, por outro, para revelar os processos que geram a cidade e conformam a cultura arquitetônica.

A elaboração e a interpretação dos fatos e eventos constituem um processo social, em que cada pesquisador acrescenta uma camada ao conhecimento anterior, de modo que caminhe em direção à verdade, mesmo sendo provisória no âmbito do entendimento do que é a ciência hoje. Como tecnologia social, a ciência depende de olhares sobre a realidade, provindos de múltiplas experiências. Nesse campo de criação de ambiente de pesquisa amplo, é possível introduzir a inseparabilidade de Pesquisa e Extensão, que se alimentam reciprocamente.

A presença ou a ausência de referências a outros textos pode conferir credibilidade e consistência às argumentações, criando múltiplas referências para ampliar as abordagens de Pesquisa. Somente um texto carregado de referências provindas da experiência multifacetada é capaz de demonstrar quanto o pesquisador tem conhecimento da própria área de pesquisa e consciência de quais controvérsias existem e, sobretudo, quais são as lacunas de conhecimento e quais fronteiras devem ser ultrapassadas.

As ciências não são autônomas, pois dependem da ação coletiva. Pesquisas acadêmicas não são realizadas apenas no interior das universidades, tampouco se mantêm restritas ao conhecimento produzido nos laboratórios; elas se estendem para além dos muros das instituições e sinalizam forte viés extensionista. Grande número de esferas abrange o pesquisador, que deve ser capaz de atuar para realizar uma investigação de impacto em sua área de atuação. A visão sistêmica, propiciada pela interdisciplinaridade, favorece essa construção e troca de conhecimentos de modo mais intenso.

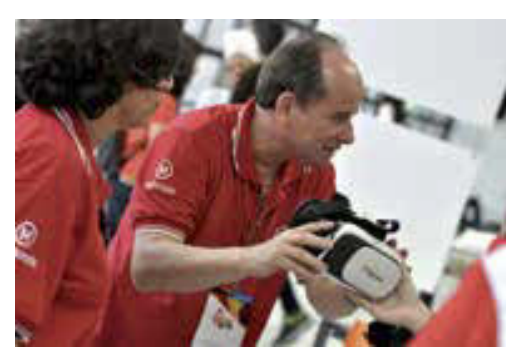

Magnífico Reitor da UPM, Prof. Dr. Benedito Guimarães Aguiar Neto, conversa com o público no Mackenzie Day, setembro de 2016. 


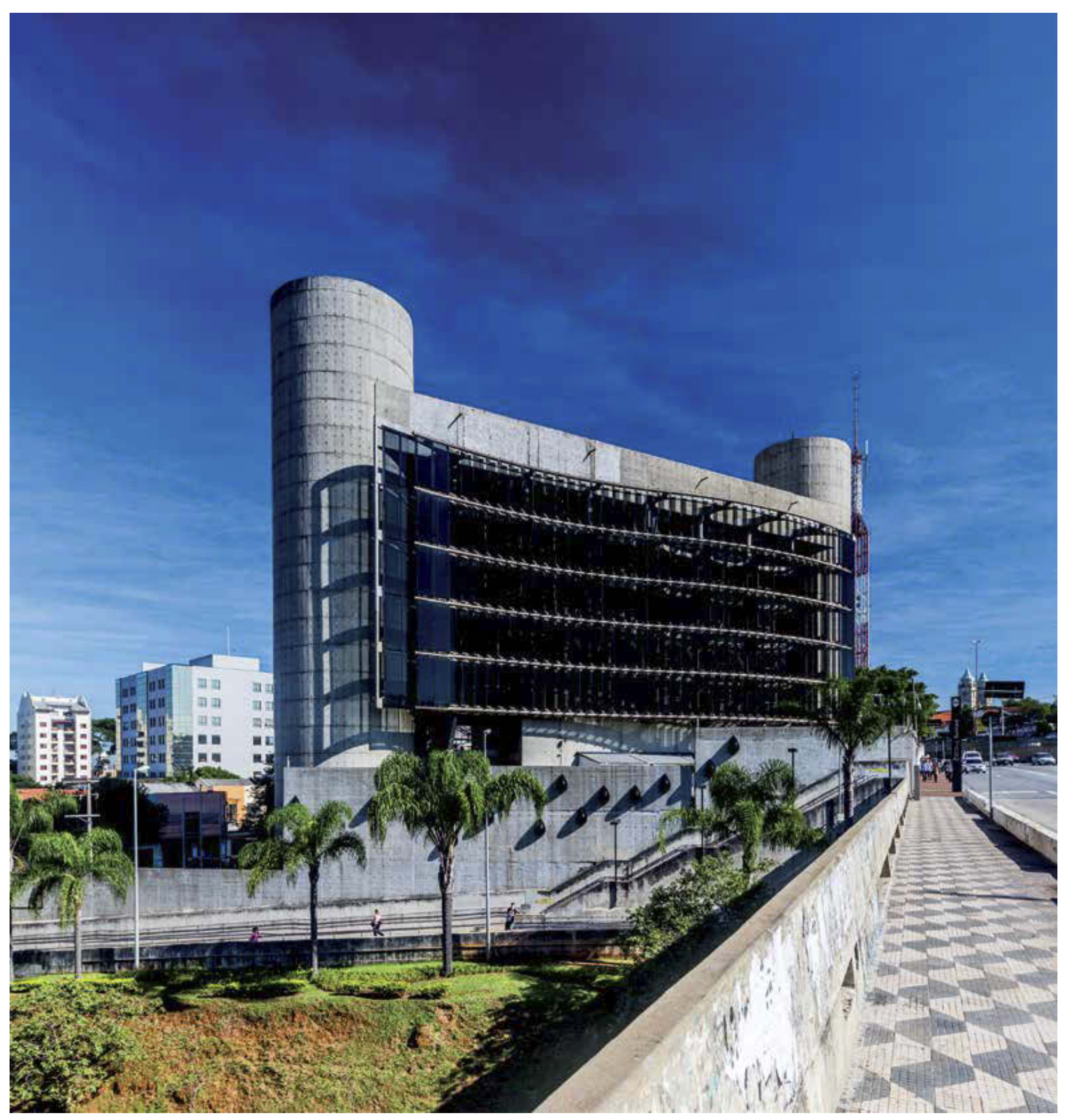


Latour (2016) diferencia o termo cogito, de Descartes, que significa o pensamento em sua acepção ideal, do termo cogitamos, uma construção coletiva do conhecimento, realizado nas experimentações em laboratórios, nas Instituições de Ensino Superior (IES) e fora delas, com o apoio de agências públicas e privadas de financiamento. Do sujeito isolado ao sujeito coletivo, é o movimento que se relaciona à Pesquisa contemporânea, no qual o conhecimento avança sob estímulo de comprovações e refutações constantes que permitem que a ciência prossiga seu rumo. A definição de Latour (2016) lança um desafio de realizar pesquisas verdadeiramente interdisciplinares, e com abertura ao mundo extra-acadêmico, com financiamento e reconhecimento.

Na atuação profissional, é fundamental ter consciência dos saberes acumulados pela área de conhecimento, e, particularmente, da disciplina com a qual se está intimamente envolvido. Nesse sentido, torna-se essencial a consciência e a autopercepção do pesquisador para se posicionar diante do domínio de seu campo de atuação. A Teoria dos Campos (Field Theory, 1994), criada por Mihaly Csikszentmihalyi, permite explicar a relação entre o indivíduo, o campo (os pares) e a área (domínio) na qual ele está envolvido.

Para suprir essa condição contemporânea da Pesquisa e Extensão, a FAU-Mackenzie, a partir de meados dos anos 2000, apostou na estrutura de Grupos de Pesquisa e elevou a ação de pesquisar à posição de oportunidade de aprimoramento contínuo do ensino, nos níveis de Graduação e Pós-Graduação.

A integração entre Pesquisa e Extensão é uma das condições fundamentais à produção de conhecimento na Universidade do século XXI, que enfrenta grandes desafios: uma nova cultura de aprendizado, produção coletiva de conhecimento científico, adaptação às novas tecnologias e à ciência em construção e financiamento e eficiência. Para as universidades enfrentarem os quatro principais desafios gerais apresentados anteriormente, os conhecimentos produzidos devem ser amplamente difundidos e disseminados, e, para isso, são fundamentais as ações extensionistas.

A Constituição Brasileira, no Capítulo III, intitulado "Da Educação, da Cultura e do Desporto", seção I, Artigo 207, define que "As universidades gozam de autonomia didático-científica, administrativa e de gestão financeira e patrimonial, e obedecerão ao princípio de indissociabilidade entre ensino, pesquisa e extensão (EC n 11/1996)" (BRASIL, 2016, p. 180). Desde então, o tripé Ensino-Pesquisa-Extensão tem sido um mote, porque não basta ensinar e produzir conhecimentos, é necessário planejar estratégias para transmiti-las a toda a sociedade. As ações de Extensão, que transcendem os muros das universidades, são formas de medida do impacto social do conhecimento.

Essa abordagem sistêmica na FAU-Mackenzie vem sendo um grande desafio há pelo menos uma década; justifica-se pelo fato de que o indivíduo, embora talentoso, somente extrai os melhores conhecimentos e desenvolve experiências e habilidades a partir de sua
Na página anterior:

Centro de Cultura Judaica, São Paulo, 2003. Projeto do Arquiteto Roberto Loeb (Mackenzie, 1965). 
4. A Extensão foi integrada oficialmente à Universidade com sua inclusão na Constituição Federal de 1988 e regulamentação pela Lei de Diretrizes e Bases (LDB) de 1996. A LDB explicita nos incisos VI e VII do artigo $43^{\circ}$ - as finalidades da educação superior:

"[...] estimular os conhecimentos do mundo presente, em particular os nacionais e regionais, prestar serviços especializados a comunidade e estabelecer com esta uma relação de reciprocidade."

E, ainda

"[...] promover a extensão aberta a participação da população, visando a difusão das conquistas e benefícios relutantes da criação cultural e da pesquisa cientifica e tecnológica geradas na instituição."

Além disso, o Plano Nacional de Extensão (2001) define Extensão Universitária como: "prática acadêmica que interliga a universidade nas suas atividades de ensino e pesquisa com as demandas da população". atuação no meio social. O campo da Pesquisa e Extensão é formado por coletividade que domina conhecimentos diversos e acumulados, e que não somente controla e influencia a área de conhecimento, mas pode ampliá-la ao compartilhar visões e perspectivas. A área, ou o domínio, é constituída pelos conhecimentos acumulados pelo campo; nela, encontram-se os juízes, os pares que arbitram debates e discussões acadêmicas. Essa é a justificativa que fundamenta os Projetos Político-Pedagógicos da FAU-Mackenzie que insistem no protagonismo estudantil e na ação coletiva de grupos e projetos de pesquisa, que se materializam com o fomento de recursos provindos de agências públicas e privadas - entre eles, o Fundo Mackenzie de Pesquisa (MackPesquisa), com excepcional contribuição à realização da Pesquisa no Mackenzie hoje.

Nesse âmbito, justifica-se cada vez mais a realização da pesquisa acadêmica e científica para o enriquecimento do ensino e da profissão de Arquiteto e Urbanista. A Extensão alia-se à Pesquisa como parte de uma ação fundamental de aplicação do conhecimento, visando o seu retorno à sociedade.

As ações de Extensão, que transcendem os muros das Universidades, são formas de mensuração do impacto social do conhecimento. ${ }^{4}$ De forma geral, a maneira mais usual de medir o impacto científico é contabilizar publicações compartilhadas pelos pares de uma mesma área de atuação. Mas o impacto social é derivado da capacidade de cada Instituição de atingir e de beneficiar pessoas em outras áreas, e de todas as idades e extratos sociais, sendo esses o objetivo e o público-alvo da Extensão. Os cursos gratuitos concedidos pelas Universidades a toda a sociedade, as ações sociais realizadas em comunidades carentes, as prestações de serviço dos pesquisadores aos menos favorecidos e as palestras e oficinas sobre temas de interesse público são alguns dos exemplos de atividades de Extensão que professores e alunos podem oferecer.

Ideias criativas podem ser testadas a partir de experimentações. Tanto as ações extensionistas que têm impacto social, bem como as ações inovadoras, com potencial de impacto econômico e tecnológico, contribuem para fortalecer a missão da Universidade na sociedade contemporânea. Além das pesquisas científicas, várias ações socioculturais podem e devem ser realizadas em benefício de toda a sociedade, uma vez que os aportes financeiros públicos e incentivos fiscais devem dar retorno a todos aqueles que contribuem com seus impostos.

Nesse contexto, vale relembrar que, no âmbito da reestruturação da UPM ocorrida entre 2004 e 2005, a estrutura departamental vigente foi suprimida e o Ensino, Pesquisa e a Extensão passaram a se organizar por unidades e cursos, e em eixos temáticos e coordenações pedagógicas. A fim de consolidar a tríade nas Unidades Universitárias, o Art. 10, da Resolução 03/2013, do Conselho Universitário da UPM, de 20 de março de 2013, define que "o objetivo das Atividades Complementares é fomentar complementação da formação acadêmica do corpo discente, contribuindo, assim, para o desenvolvimento de competências e de habilidades imprescindíveis à formação profissional". 
Ainda em seu Art. $7^{\circ}$, a resolução estabelece que:

[...] as Atividades Complementares têm a finalidade de enriquecer o processo de ensino-aprendizagem destinando-se a:

I - Ampliar os horizontes do conhecimento, bem como de sua prática, para além da sala de aula, em atividades de ensino, de pesquisa e de extensão, viabilizando sua integração complementar à formação profissional e social;

II - Encorajar o reconhecimento de conhecimentos, habilidades e competências adquiridas fora do ambiente escolar, inclusive as que se referirem às experiências profissionalizantes, julgadas relevantes para a área de formação considerada;

III - Estimular práticas de estudo independentes, visando à progressiva autonomia profissional e intelectual do aluno;

IV - Propiciar a inter e a transdisciplinaridade no currículo, dentro e entre os semestres;

V - Fortalecer a articulação da teoria com a prática, valorizando tanto a pesquisa individual e coletiva quanto a participação em atividades de extensão;

VI - Favorecer o relacionamento entre grupos e a convivência com as diferenças sociais no contexto regional em que se insere a instituição.

A Reitoria, ainda preocupada com a qualidade do Ensino, da Pesquisa e da Extensão, adota políticas institucionais que constam da Visão 150, plano que estabelece uma série de diretrizes que norteiam a atuação de todos os segmentos e instâncias da UPM no Plano de Desenvolvimento Institucional (PDI) 2013-2018. O PDI orienta que as ações devem atender a um perfil de formação holística de concepção dos fenômenos naturais, do meio ambiente e da sociedade, contudo, sem abandonar demandas mais específicas da sociedade, por meio do ensino, da pesquisa e da extensão universitária.

Na FAU-Mackenzie, Pesquisa e Extensão na atualidade integram o processo de ensino-aprendizagem, tendo na experimentação importante protagonista, ao envolver docentes e discentes, da Graduação à Pós-Graduação. No último Projeto Político-Pedagógico dos seus cursos de Graduação (FACULDADE DE ARQUITETURA, 2013) previu-se a incorporação de instrumentais ao processo de ensino-aprendizagem em que a experimentação e a ação do estudante e seu protagonismo na produção de conhecimento são o cerne da formação universitária, incentivando-se o uso dos diversos laboratórios nas disciplinas regulares, a participação em projetos de pesquisa, realização de Iniciação Científica (IC) e de atividades extensionistas. O Projeto Pedagógico visou eliminar a fragmentação do conhecimento e a especialização precoce, diminuindo o número de disciplinas, valorizando a formação continuada e a escolha de componentes curriculares pelo aluno, possibilitando modalidades diversas para a prática da tríade Ensino, Pesquisa e Extensão.

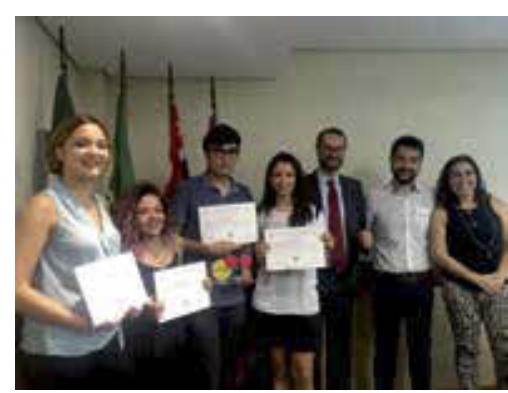

Evento de premiação do Desafio OpenLab São Paulo 2030 (Mobilidade e a Cidade do Futuro). Concurso promovido no segundo semestre de 2016 pela FAU-Mackenzie em parceria com o Instituto Cidade em Movimento (IVM-Brasil) e com apoio do Grupo PSA. Da esquerda para a direita, Luiza Andrada e Silva, Diretora-Executiva do IVM-Brasil, Prof. Luís Alexandre Ogasawara (Curso de Design e Coordenador do concurso), Emmanuel Hedouin, do Grupo PSA, e a Equipe 1 vencedora recebendo o troféu e os certificados. 
Linha 1 - Azul (Norte - Sul), do Metrô,

São Paulo, anos 1970. Projeto dos

Arquitetos Marcello Fragelli (Coordenador

Geral), Vasco de Mello (Mackenzie,

1964), Luiz Gonzaga de Oliveira

Camargo (Mackenzie, 1966), Álvaro de

Macedo Neto (Mackenzie, 1966), Flavio

Marcondes (Mackenzie, 1966), Silvio John

Heilbut (Mackenzie, 1966) e João Batista

Martinez Corrêa (Mackenzie, 1967).

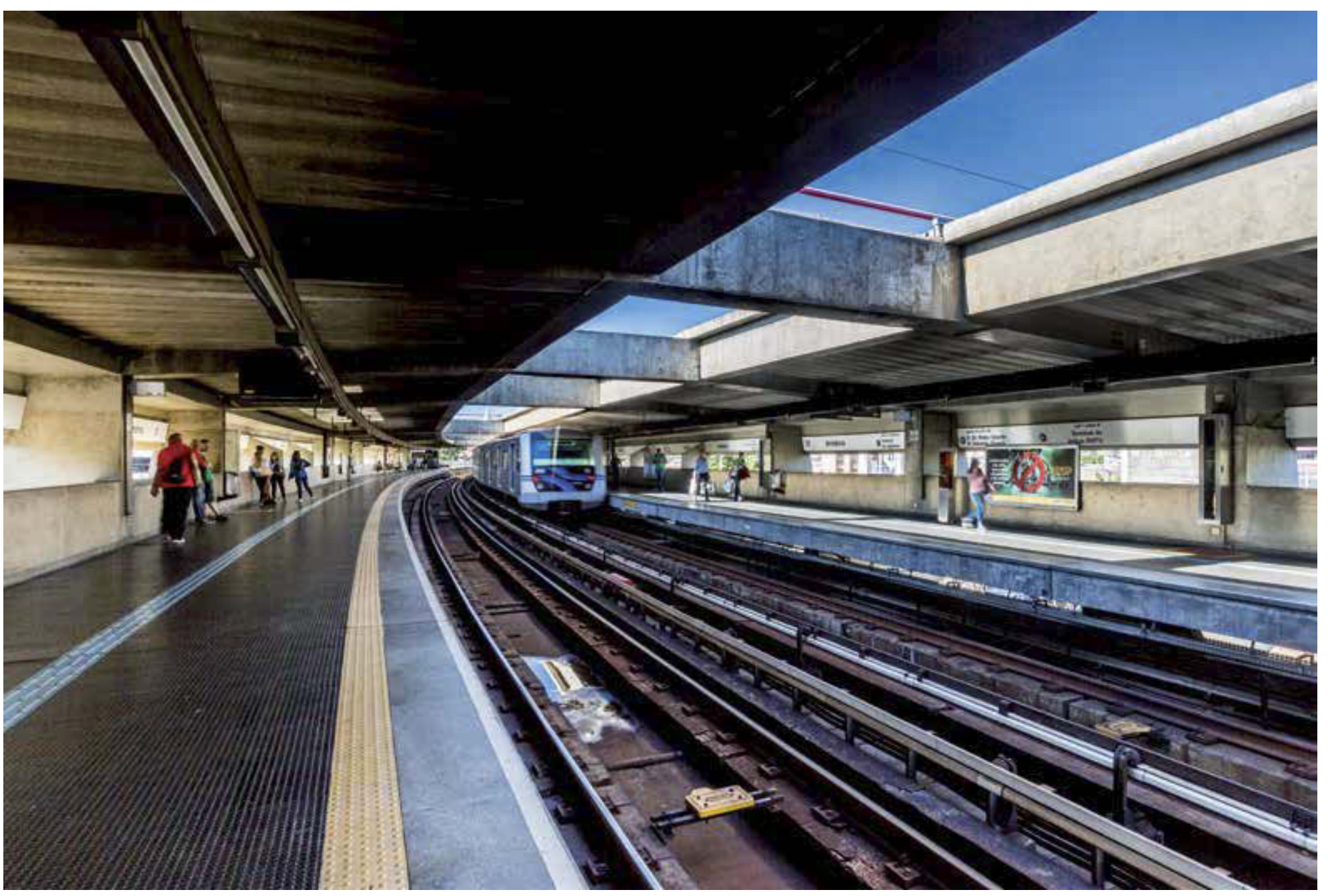




\section{A Pesquisa na FAU-Mackenzie: da Iniciação Científica aos Grupos de Pesquisa}

Inicialmente, a Pesquisa na FAU-Mackenzie estava restrita aos docentes da Pós-Graduação, e tinha como principal financiador MackPesquisa, órgão vinculado ao Instituto Presbiteriano Mackenzie, que financiou importantes projetos de pesquisa para a consolidação do Programa em sua etapa inicial. Em 2004, como já ressaltado, deu-se a formação de vários Grupos de Pesquisa com chancela do CNPq, articulando docentes e discentes de Graduação e Pós-Graduação, permitindo iniciar uma nova etapa de contínua alimentação do Ensino pela Pesquisa e Extensão.

Os Grupos de Pesquisa elaboraram seu patrimônio intelectual fundamentado na atividade de investigação científica - do Doutorado à Iniciação Científica. Atualmente, a FAU-Mackenzie conta com 22 grupos de pesquisa devidamente cadastrados no CNPq e certificados pela instituição, sendo 20 alocados no Curso de Arquitetura e Urbanismo, e dois, no Curso de Design.

A Iniciação Científica é importante protagonista nesse contexto, permitindo que professores e alunos, principalmente aqueles que ainda não participam da Pós-Graduação, adentrem o universo da Pesquisa.

O Programa Institucional de Bolsas de Iniciação Científica (Pibic) do Mackenzie foi estruturado na UPM pelo Ato da Reitoria n 47/2003, de forma inteiramente compatível com as determinações do CNPq, contando com subsídios não só da Entidade Mantenedora da Universidade, como também do MackPesquisa. Em 2005, a UPM obteve o credenciamento de seu Pibic no CNPq, quando foram concedidas 24 bolsas Pibic/CNPq; em 2006, a universidade disponibilizou mais seis cotas, totalizando 30 bolsas Pibic/CNPq, as quais foram mantidas para o período de agosto de 2007 a julho de 2008. Atualmente, o CNPq disponibiliza 42 bolsas de Iniciação Científica.

A Iniciação Científica é um período especial, quando os estudantes de Graduação, sob a supervisão de seu orientador, têm a possibilidade de se integrar, por meio da vivência em pesquisa, com mestrandos e doutorandos. Esses objetivos são alcançados pelo envolvimento do aluno em atividades práticas e teóricas de Pesquisa, sob a orientação de um professor-pesquisador e principalmente pela participação em um Grupo de Pesquisa, convivendo com pesquisadores de diversos níveis. Os resultados são apresentados nas Jornadas de Iniciação Científica, eventos realizados anualmente pela Pró-Reitoria e Pós-Graduação via Coordenadoria de Pesquisa da UPM. ${ }^{5}$

Até 2016, a Iniciação Científica da UPM incluía dois processos seletivos: no início do semestre letivo, contando com bolsas subsidiadas pelo MackPesquisa, e, em agosto, com bolsas subsidiadas pela Entidade Mantenedora da UPM e pelo CNPq. A partir de 2017, o processo passou a ser anual. O número de projetos inscritos tem sido crescente a cada processo
5. A Jornada de Iniciação Científica da UPM encontra-se em sua $13^{a}$ edição.

Promovida pela Pró-Reitoria de Pesquisa e Pós-Graduação, via Coordenadoria de Pesquisa, atualmente, se soma à Mostra de Iniciação em Tecnologia e Inovação e à Mostra de Extensão, ambos eventos de responsabilidade da Pró-Reitoria de Extensão e Educação Continuada. As pesquisas desenvolvidas pelos alunos do Programa Institucional de Bolsas de Iniciação Científica (Pibic) e do Programa Institucional Voluntário de Iniciação Científica (Pivic) são apresentadas durante o evento e posteriormente publicada em seus anais. 
seletivo, propiciando relevante e dinâmico vínculo entre o Ensino e a Pesquisa na Graduação, assim como proporcionando a contínua integração entre os docentes da Pós-Graduação com os discentes dos diversos Cursos de nossa UPM.

Na FAU-Mackenzie, muitos alunos de Graduação receberam bolsa do Programa Institucional de Bolsas de Iniciação Científica (Pibic); o primeiro processo Pibic-Mackenzie para a Arquitetura e Urbanismo iniciou-se em março de 2004 com 33 bolsistas e 42 voluntários. Até 2017, cerca de 500 alunos estiveram envolvidos com o Pibic, 80\% deles provenientes do Curso de Arquitetura e Urbanismo.

\section{Quadro 1 - Relação dos Grupos de Pesquisa em funcionamento na FAU-Mackenzie (2017)}

\begin{tabular}{|c|c|}
\hline GRUPO & LÍDER(ES) \\
\hline A Paisagem da Cidade Sustentável & Pérola Felipette Brocaneli \\
\hline Arquitetura e Construção & Maria Augusta Justi Pisani e Valter Caldana \\
\hline Arquitetura Ensino e Profissão & Eunice Helena Sguizzardi Abascal \\
\hline Arquitetura: Projeto \& Pesquisa \& Ensino & Rafael Antonio Perrone \\
\hline Arquitetura: Projeto e Crítica & Maria Isabel Villac \\
\hline Arquitetura, Processo de Projeto e Análise Digital & Wilson Florio \\
\hline $\begin{array}{l}\text { A Construção da Cidade: Arquitetura, Documentação } \\
\text { e Crítica }\end{array}$ & Marcos José Carrilho \\
\hline Cidades e Edifícios Sustentáveis & Gilda Collet Bruna \\
\hline Cidade, Arquitetura e Filosofia & Igor Guatelli \\
\hline Design, Arte, Linguagens e Processos & Ariane Daniella Cole \\
\hline Design, Teoria e Projeto & Nara Silvia M. Martins \\
\hline $\begin{array}{l}\text { Estratégias Projetuais em Territórios Urbanos/ } \\
\text { Degradados e Portuários }\end{array}$ & Carlos Andrés Arriagada \\
\hline Laboratório de Projetos e Políticas Públicas & Valter Caldana \\
\hline $\begin{array}{l}\text { Paradigmas para o Estudo de Cidades Ibero-americanas } \\
\text { no Século XXI }\end{array}$ & Eunice Helena Sguizzardi Abascal \\
\hline Políticas Públicas e Habitação Social & Denise Antonucci \\
\hline $\begin{array}{l}\text { Projetos Urbanos e Desenvolvimento Urbano } \\
\text { Sustentável }\end{array}$ & Carlos Leite de Souza \\
\hline $\begin{array}{l}\text { Questões Urbanas: Design, Arquitetura, Planejamento, } \\
\text { Paisagem }\end{array}$ & Mauro Claro \\
\hline Sistemas Construtivos na Arquitetura Contemporânea & Celia Moretti Meirelles \\
\hline Teoria e Projeto na Era Digital & Eduardo Sampaio Nardelli \\
\hline Urbanismo Brasileiro e Ibero-americano & José Geraldo Simões Jr. \\
\hline Urbanismo Contemporâneo, Redes, Sistemas e Processos & Angélica Tanus Benatti Alvim e Luiz G. R. de Castro \\
\hline Verticalização, Patrimônio Cultural e Urbanidade & Nadia Somekh \\
\hline \multicolumn{2}{|l|}{ Fonte: Elaborado pelos autores. } \\
\hline 280 & \\
\hline
\end{tabular}




\section{O Fórum de Pesquisa FAU-Mackenzie: breve histórico ${ }^{6}$}

Criado em 2005, o Fórum de Pesquisa nasceu como uma realização endógena, tendo sido aberto ao público externo a partir de 2008. Em 2010, foi consolidado em âmbito nacional, com repercussões internacionais. Concebido como espaço privilegiado de debate das pesquisas em Arquitetura e Urbanismo e Design, pretendeu valorizar e aprofundar a inter e a transdisciplinaridade. ${ }^{7}$

Em seu início, constituiu-se no âmbito da II Semana Viver Metrópole (Semana de Arquitetura e Urbanismo e Design da FAU-Mackenzie) ${ }^{8}$ com o objetivo de disseminar e integrar a pesquisa aos diversos níveis de ensino - da Pós-Graduação à Graduação.

Entre os anos de 2005 e 2007 o evento, organizado pela Coordenação de Pesquisa e Extensão (Copex), ${ }^{9}$ era realizado pelos Grupos de Pesquisa, que concebiam atividades como apresentação de trabalhos e mesas de debates envolvendo diversos pesquisadores internos e externos, convidados para compartilhar pesquisas e difundir suas atividades. Os dois primeiros fóruns obtiveram sucesso expressivo, com total adesão dos Grupos de Pesquisa, atraindo alunos interessados nas atividades, quer de Iniciação Científica, quer de Pós-Graduação.

Nessa primeira fase, houve importantes avanços, com destaque para o reconhecimento e consequente fortalecimento dos Grupos de Pesquisa no âmbito da própria Unidade e da Universidade, assim como a publicação de artigos científicos, frutos de pesquisas em andamento, nos Anais do evento e em site específico, estimulando alunos e professores a sistematizarem o conhecimento para a sua divulgação.

Nos anos de 2008 e 2009, o evento inicia sua segunda fase, buscando remodelar seu formato. Organizado pela Coordenação de Pesquisa e com a participação das Coordenações de Extensão e de Pós-Graduação Stricto Sensu, ${ }^{10}$ propôs-se um novo desenho, procurando integrar os Grupos de Pesquisa, estabelecer interlocuções entre os trabaIhos dos Cursos de Arquitetura e Urbanismo e Design em andamento, registrar o estado da arte das pesquisas nesses campos do conhecimento e, principalmente, divulgar às comunidades interna e externa a produção dos Grupos de Pesquisa da FAU-Mackenzie, favorecendo sua integração a todas as instâncias de ensino e pesquisa da Escola - da Iniciação Científica ao Doutorado. A partir do $4^{\circ}$ Fórum de Pesquisa, ${ }^{11}$ o evento foi indexado ${ }^{12}$ e os artigos, selecionados e publicados digitalmente.

Ao comemorar cinco anos do Fórum de Pesquisa FAU-Mackenzie, ${ }^{13}$ e, ao mesmo tempo, dando o passo inicial para a sua terceira fase, aberta à comunidade nacional, definiu-se como tema central Retrospectivas e Desafios para a Pesquisa em Arquitetura e Urbanismo. Compreendeu-se que era necessário iniciar maior interlocução com as agências de fomento, disseminando a pesquisa da FAU-Mackenzie em âmbito maior. Naquele momento, foi fundamental a participação de pesquisadores representantes de área no CNPq: Prof. Marco Aurélio
6. Texto com base em Alvim e Abascal (2012).

7. "[...] Um dos principais pressupostos para se caminhar interdisciplinarmente é o diálogo, para se reconhecer aquilo que falta de um lado e que pode ou deve receber do outro. Ou [...] quebrar o isolamento disciplinar pela negociação de pontos de vista, projetos e interesses divergentes/convergentes" (CALEGARE; SILVA JR., 2012, p. 240).

8. A Semana Viver Metrópole foi criada em 2004 pelo Diretório Acadêmico da

Faculdade de Arquitetura Mackenzie

(Dafam) em parceria com um grupo de professores. Atualmente, encontra-se em sua $15^{a}$ edição.

9. O Coordenador de Pesquisa e Extensão, entre 2005 e 2006, era o Prof. Dr. Carlos Leite de Souza.

10. Entre os anos de 2008 e 2010, a Coordenação de Pesquisa esteve sob a responsabilidade da Profa. Angélica Tanus Benatti Alvim, a Coordenação de Extensão, da Profa. Eunice Abascal, e a Coordenação de Pós-Graduação, da Profa. Maria Isabel Villac.

11. No $4^{\circ}$ Fórum, organizou-se a produção dos Grupos de Pesquisa a partir dos Eixos Temáticos que estruturavam na ocasião o ensino na escola, com a participação de um conjunto de pesquisadores de renome nacional para aprofundar os debates: Projeto - Prof. João Walter Toscano (USP); Urbanismo - Profa. Heloisa Soares Moura Costa (UFMG e CNPq):

Fundamentação e Crítica - Profa. Monica Junqueira (FAU-USP), e Sustentabilidade + Tecnologia Prof. Marcelo Romero (USP); Design: teoria e projeto - Prof. Ari Antonio da Rocha, (FAAP); Design de comunicação: formas visuais de narração, interação e representação - Profa. Maria Cecília Loschiavo dos Santos (USP); Design, arte, linguagens e processos Prof. Marcos Rizzoli (UPM).

12. Os artigos dos Grupos de Pesquisa e dos conferencistas foram publicados em meio digital ISSN: 2176-1809.

13. Nessa ocasião, o Fórum foi indexado pelo ISBN, quando os artigos científicos foram publicados em seus Anais em formato digital. 
Casa Bola, São Paulo, 1979. Projeto do Arquiteto Eduardo Longo

(Mackenzie, 1966).

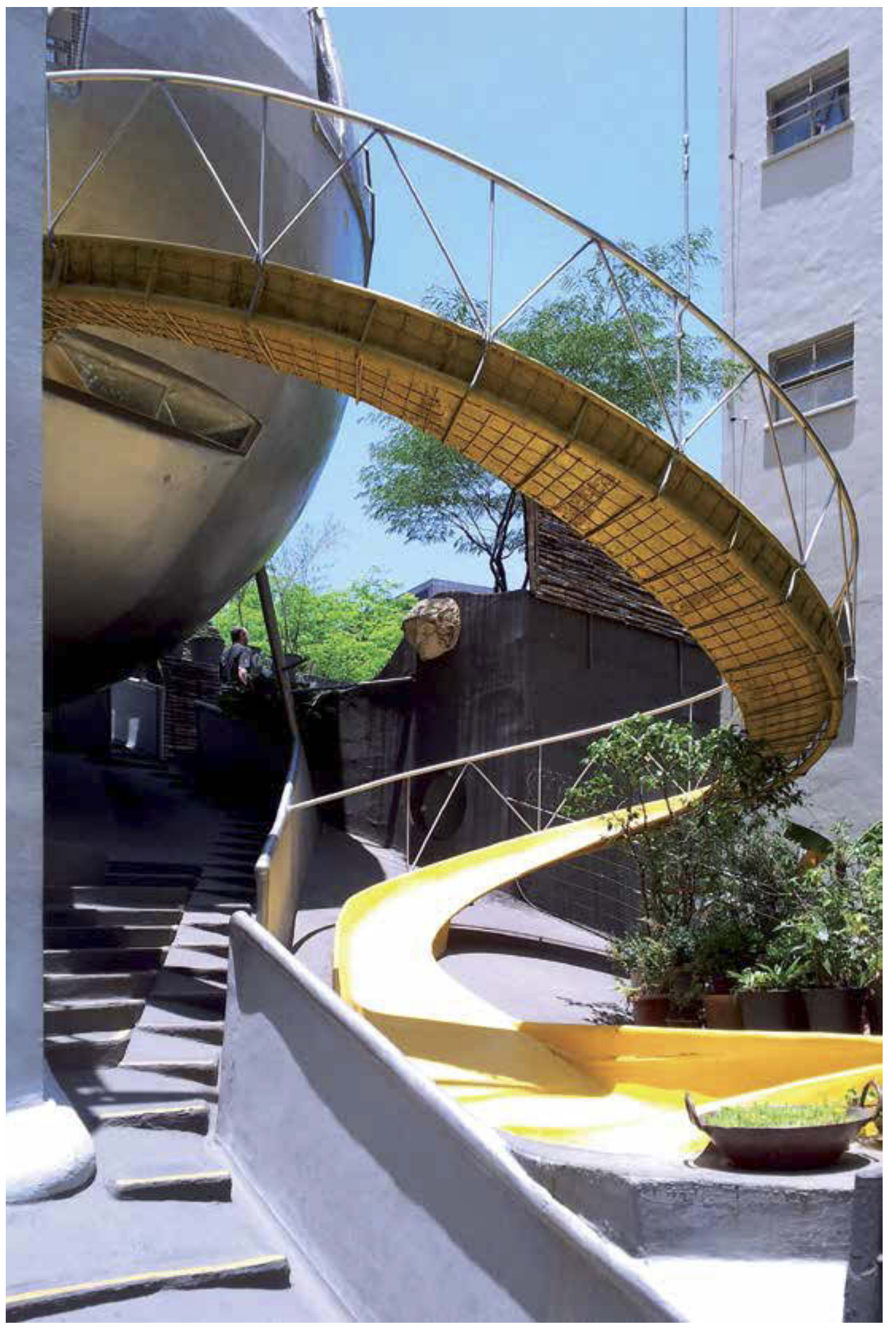


Andrade Filgueiras Gomes (UFBA), representando a Arquitetura e o Urbanismo; e Profa. Maria Cecilia Loschiavo dos Santos (FAU-USP), representando a área de Design.

Ampliou-se a Comissão Organizadora envolvendo todas as áreas de conhecimento da Escola, tendo, então, sido proposto um comitê científico, ainda em âmbito interno, integrado pelos pesquisadores mais destacados, responsáveis por selecionar os melhores artigos a serem apresentados nas diversas mesas do Fórum. Essas mesas foram organizadas a partir das seguintes temáticas de pesquisas em curso: Arquitetura Moderna e Cidade; Cidade, Ambiente e Política Pública; Design, Cultura e Ambiente; Habitação, Mercado e Ambiente; Pesquisa, Ensino e Tecnologia; Política e Projeto Urbano; Projeto e Meio Ambiente; Projeto e Cultura; Projeto, Representação e Processo Criativo; Projeto, Construção e Cidade; Urbanização e Meio Ambiente.

Entre 2010 e 2014, em sua terceira fase, e, respectivamente, a partir de sua $6^{\text {a }}$ edição, ${ }^{14}$ o evento assumiu o formato recente, aberto à comunidade científica nacional.

As últimas edições do evento estruturaram-se em três frentes: conferências de pesquisadores de renome nacional e internacional; sessões de comunicação com apresentação de um conjunto de artigos selecionados; e mesas-redondas, com o objetivo de estabelecer diálogos e interlocuções que expressam uma amostra do universo de pesquisas produzidas pelos Grupos de Pesquisa, em instituições de ensino.

Sob o tema geral Pesquisa em Arquitetura e Urbanismo e Design: interlocuções e perspectivas, o $6^{\circ}$ Fórum teve como objetivos diálogos e interlocuções entre Arquitetura e Urbanismo e Design, enfatizando o estado da arte das pesquisas nesses campos do conhecimento. Procurou ainda divulgar informações e experiências referentes a abordagens, tipos de pesquisa, abrangência e metodologias, e aprofundar e debater a produção de conhecimento realizada nacionalmente.

O $7^{\circ}$ Fórum, cujo tópico foi Pesquisa em Arquitetura Urbanismo Design: Transdisciplinaridades, assumiu a reflexão crítica contemporânea em Arquitetura e Urbanismo e Design como expressão de relações e afinidades possíveis de campos temáticos. Com base no entendimento de que a transdisciplinaridade compreende diálogos e um amplo e complexo tecido de relações a partir da aproximação de disciplinas e saberes, apostou na possibilidade de articulação recíproca entre conhecimento prático e teórico, ensino e crítica.

O $8^{\circ}$ Fórum de Pesquisa, intitulado A Condição Contemporânea do Projeto: Arquitetura, Urbanismo e Design, abordou o projeto como agenciamento, mediação de temas e agendas complexas, como proposta para nossa condição histórica. Além disso, teve outros temas, tais como o projeto como instrumento de participação social - Projeto Inclusivo e de Ecologia Reverencial, Projeto, Programa e Agenciamento foram tratados. Nesse momento, também foi realizada a Conferência inaugural Mil Palavras-Chave sobre a Condição Contemporânea do Projeto.
14. A partir da experiência do $5^{\circ}$ Fórum de Pesquisa, em agosto de 2009

como coordenadora de Pesquisa, a Profa. Angélica Tanus Benatti Alvim idealiza seu novo formato e submete-o ao MackPesquisa para obtenção de recursos, recebendo parecer positivo em dezembro. Em abril de 2010, assume a Coordenação de Pesquisa a Profa. Eunice Helena Abascal, e juntamente com a Profa. Angélica Tanus Benatti Alvim, que assume a função de Coordenadora do Programa de Pós-Graduação, organizam os dois eventos abertos. Os Coordenadores de Extensão, Prof Charles Vincent (2008-2010) e Prof. Paulo Corrêa (2011) contribuem ativamente articulando o evento à Semana Viver Metrópole, organizada pelos alunos dos Cursos de Graduação. Entre os anos de 2013 e 2014, a Coordenação de Pesquisa esteve sob responsabilidade da Profa. Denise Antonucci, que deu continuidade à oitava edição do evento. 
15. No $6^{\circ}$ Fórum, organizaram-se as seguintes Sessões de Comunicação: Ambiente Construído; Memória e Identidade; Arquitetura Moderna e Cidade; Ensino e Práticas Projetuais; Espaço Urbano, Sustentabilidade e Projeto; Habitar a Cidade

Contemporânea; Tecnologia, Projeto e Sustentabilidade. No $7^{\circ}$ Fórum, organizaram-se as seguintes Sessões Temáticas: Ambiente, Projeto e Materialidade; Práxis e Proposição Teórica; Ambiente Construído, Projeto e Gestão do Território; Arte e Cidade; e Tecnologia, Experimentação e Projeto. No $8^{\circ}$ Fórum, foram organizadas Sessões Temáticas, denominadas A\&U e DI, e Mesas-Redondas, além de Conferências.
As conferências de Pesquisadores, Arquitetos e Designers buscaram enfatizar o papel da pesquisa em projeto em suas diversas escalas.

As mesas-redondas constituíram-se em locais privilegiados de estímulo a intercâmbios de conhecimento e divulgação dos avanços das pesquisas. Foram propostas pelos Grupos de Pesquisa de diversas Instituições de Ensino, que de certa forma possuem parcerias e/ou interlocuções com os Grupos de Pesquisa da FAU-Mackenzie. Nas mesas das últimas edições, contaram-se com interlocutores privilegiados, com experiência na atuação e na política de fomento à Pesquisa das agências de pesquisa - CNPq, Capes e Fapesp -, debatendo as especificidades da Pesquisa na área de Arquitetura e Urbanismo e Design.

Os artigos destinados às Sessões de Comunicação foram submetidos ao Comitê Científico e passaram por seleção rigorosa; em seguida, foram apresentados e publicados nos Anais do Evento. ${ }^{15}$ De modo geral, os artigos selecionados, frutos de pesquisas concluídas ou em andamento, foram distribuídos em sessões organizadas a partir de temas que se inter-relacionavam.

As mesas-redondas e artigos propostos evidenciam amplo leque de assuntos inter e transdisciplinares, que refletem sobre teoria e prática, em suas diversas escalas - do objeto ao urbano/regional -, congregando temas como: fundamentos teóricos; história; processos e métodos de projetação; ensino; representação; arte e cultura; processos construtivos; tecnologias e modelagem; políticas públicas; gestão do espaço e do objeto; meio ambiente e sustentabilidade urbana e ambiental, entre outros.

O percurso do evento contribuiu para a maior integração entre a Pós-Graduação e os dois cursos de Graduação, para o avanço da produção do conhecimento científico sobre as temáticas em que atuamos, e, principalmente, para a ampliação dos intercâmbios com outras Instituições de Ensino, possibilitando o desenvolvimento de pesquisas conjuntas, eventos, convênios, entre outros.

\section{A Extensão na FAU-Mackenzie}

A FAU-Mackenzie vem se mostrando proativa no campo da Extensão ao enfatizar o relacionamento dinâmico da tríade ensino, pesquisa e extensão com a rotina acadêmica. É hoje da natureza de seu funcionamento pedagógico a abertura do conhecimento produzido em pesquisa e disseminado em sala de aula à comunidade, quer científica, quer acadêmica e à sociedade em geral, sem distinção de classe, raça ou gênero. A Arquitetura, por se compreender como arte e técnica a serviço da sociedade, afirma por definição o ímpeto de se estender para além dos estreitos e tímidos limites universitários. Por essa razão, o trabalho da Coordenação de Extensão tem sido estimular essa comunidade ativa e empenhada à consolidação extensionista, na figura de Programas, Projetos e Eventos que possam ganhar em densidade, por sua importância, alcance e vitalidade sociais. 
Após 2005, a UPM instituiu a Coordenação de Extensão nas Unidades Acadêmicas, que é então exercida pelo Coordenador de Extensão, ${ }^{16}$ nomeado pelo Reitor, sendo o órgão responsável por zelar pela excelência das atividades de extensão na unidade.

Conforme orienta o Projeto Pedagógico do Curso de Arquitetura e Urbanismo de 2013, a Coordenação de Extensão da FAU-Mackenzie pauta-se por uma política que contempla os seguintes aspectos: a harmonia com o pensamento institucional da UPM, sua Missão, Visão e seus Princípios Institucionais, o pleno envolvimento de alunos da Graduação à Pós-Graduação, a elaboração de propostas que contribuam para o desenvolvimento cultural, científico e tecnológico da universidade, assumindo um compromisso com "o desenvolvimento do ser humano na sua integralidade, respeitando o meio ambiente; e que permita a socialização do conhecimento" (FACULDADE DE ARQUITETURA, 2013, p. 90).

São também previstas a interdisciplinaridade e a indissociabilidade entre Ensino, Pesquisa e Extensão. A Extensão visa o desenvolvimento docente e das atividades de pesquisa e da habilidade acadêmica dos alunos envolvidos, de sua vivência profissional a integração de conhecimentos teóricos e práticos (FACULDADE DE ARQUITETURA, 2013, p. 90).

Ao entender as atividades de Extensão como integrantes e essenciais à formação discente, o Projeto Pedagógico (2013) caracteriza as seguintes atividades:

a) consultoria ou participação consultiva em instituições privadas ou da administração pública;

b) cursos de difusão cultural ou de extensão universitária, visando a propagar conhecimentos para o tecido social, conscientizando-o de aspectos sociais ou culturais relevantes;

c) palestras, conferências e simpósios, tendo como alvo a difusão de conhecimentos especializados e o intercâmbio com profissionais e especialistas. A outra modalidade, também relacionada às práticas da docência e profissional, como também à pesquisa, mas que se diferencia da primeira em virtude de sua abrangência, responsabilidade ou custos operacionais envolvidos, necessitando, portanto, do estabelecimento de convênios ou da elaboração de documentos bilaterais, caracterizando-se por:

d) elaboração de planos diretores, urbanísticos e paisagísticos para municípios carentes de corpo técnico adequado ou sem possibilidades orçamentárias para a utilização dos serviços de escritórios profissionais especializados;

e) planejamento e orientação de projetos arquitetônicos que representem efetivamente propostas inovadoras ou modelos didáticos para a comunidade;

f) serviços técnicos especializados nas condições ambientais, que envolvam aspectos ergonômicos ou sanitários;

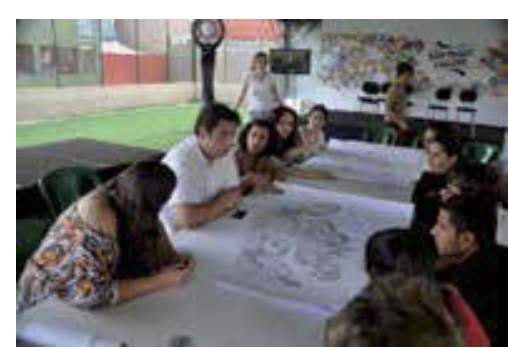

Participação de alunos e professores da FAU-Mackenzie na Jornada da Habitação - SÃO PAULO CALLING, evento organizado em 2012/1, pela Sehab/ PMSP, que contou com o Projeto de Extensão da Escola. Na foto, o Arquiteto Marcos Boldarini e as Professoras Angélica Tanus Benatti Alvim e Maria Augusta Justi Pisani discutem com alunos da Graduação e da Pós-Graduação em Arquitetura e Urbanismo aspectos da intervenção proposta no Loteamento Cantinho do Céu.

16. Na FAU-Mackenzie, os Coordenadores de Extensão, nos diferentes períodos (2008 a 2016), foram: Prof. Carlos Leite, Profa. Eunice Helena S. Abascal, Prof. Marcelo Oliveira, Prof. Charles Vincent, Prof. Paulo Correa, Prof. Eduardo Sampaio Nardelli. No período entre 2016/2 a 2017/1, as Profas. Pérola Felipette Brocaneli e Nara Silvia Martins são responsáveis pela Extensão na Unidade, atuando como Coordenadora e Coordenadora adjunta, respectivamente. 
Centro Cultural São Paulo, 1982.

Projeto dos Arquitetos Eurico Prado

Lopes (Mackenzie, 1963) e Luiz Telles

(Mackenzie, 1966).

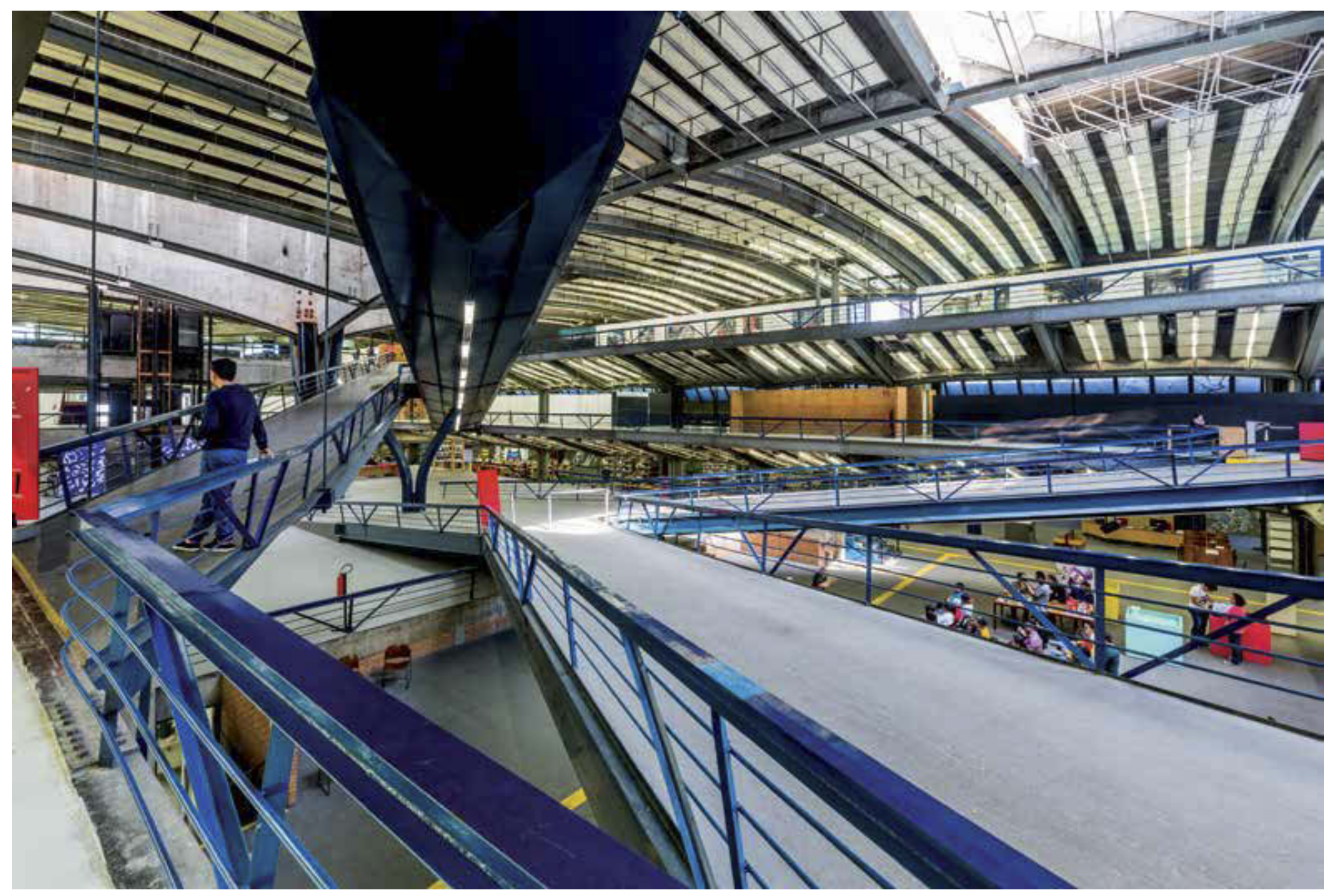


g) cursos de extensão ou especialização, presenciais ou a distância, que necessitam formalização, por envolverem outras entidades (públicas ou privadas) e responsabilidades financeiras de maior vulto (FACULDADE DE ARQUITETURA, 2013, p. 90-91).

Na FAU-Mackenzie, a Extensão perpassa diferentes instâncias de Ensino e Pesquisa, de forma que um projeto extensionista pode ser idealizado em sala de aula, acolhido em um grupo de pesquisa e alcançar desenvolvimento técnico nos vários laboratórios, para desenvolver-se parcialmente no Núcleo de Pesquisa e Extensão em Arquitetura e Urbanismo (NAU), no MoSalco Escritório Modelo de Arquitetura e Urbanismo (Emau) e na Empresa Júnior. Além de poder se valer de todos os laboratórios e espaços comuns à Escola para as experimentações físicas, os projetos vinculados às atividades de Extensão podem utilizar o canteiro experimental, espaço que conta com enorme potencial para ampliação de seu uso. Idealizado para o desenvolvimento de atividades experimentais relativas à prática construtiva, as atividades de Pesquisa e Extensão no canteiro buscam incentivar o pensamento crítico.

Projetos e Programas de Extensão contam com a participação de alunos e professores dos cursos de Graduação e Pós-Graduação em Arquitetura e Urbanismo e Design. Desde meados dos anos 2000, muitos foram os programas e projetos extensionistas desenvolvidos, promovidos por docentes e discentes. Podemos destacar alguns que, ao longo dos anos, obtiveram mais repercussão:

Design Possível: caracterizado como projeto inovador para o desenvolvimento de propostas fundamentadas em preceitos de autogestão e sustentabilidade atuando em rede, este projeto foi pioneiro na Escola em meados dos anos 2000. Liderado por docentes do Curso de Design, ${ }^{17}$ desde sua origem visou o desenvolvimento social ao aplicar o design para desenvolver produtos, executar gestões produtivas, contribuindo para geração de renda, desenvolvimento humano e social em comunidades carentes. O Design Possível também se articulou com o Programa MackVida, coordenado pelo então Decanato de Extensão (DEX), atual Pró-Reitoria de Extensão e Educação Continuada (PREC), como política extensionista universitária.

MoSalco Escritório Modelo de Arquitetura e Urbanismo (Emau): apoia atividades relacionadas ao cotidiano da prática profissional, por meio de desenvolvimento de projetos arquitetônicos, conforme define o Projeto Pedagógico do Curso de Arquitetura e Urbanismo (2013). Além disso, dá suporte para atividades de Extensão, dentre as quais se pode ressaltar o Programa de Extensão Comunidade Mackenzie: Arquitetura e responsabilidade social no entorno do campus Itambé, vinculando o trabalho do MoSalco ao Programa MackVida, apoiado pela Pró-Reitoria de Extensão e
17. O projeto teve como Coordenador o Prof. Ivo Eduardo Roman Pons e contou com ampla participação dos docentes do Curso, especialmente da Profa. Nara Martins. 


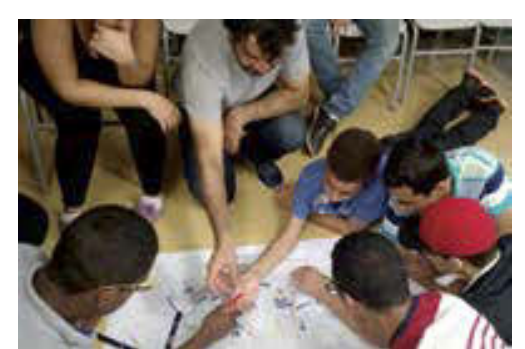

Projeto de Extensão integrado à atividade Tópicos Especiais em 2017/1: Imagine Paraisópolis - Oficina de Produção de Lugar. Responsável pelo Projeto: Prof. Ms. Wagner Resende (Doutorando do PPGAU/FAU-Mackenzie), integrante do Grupo de Pesquisa Urbanismo Contemporâneo, Redes, Sistemas e Processos (Líderes: Profa. Dra. Angélica Tanus Benatti Alvim e Prof. Dr. Luiz Guilherme Rivera de Castro).

18. A Associação Brasileira Beneficente Aslan (Abba) é uma entidade ligada à comunidade cristã que associa igrejas locais no trabalho de resgate de crianças e adolescentes em situações de risco social. Disponível em: <http://abbabrasil. com.br/>.

19. O projeto tem como coordenador o Prof. Mauro Claro e conta com ampla participação dos docentes do Curso de Design e Arquitetura e Urbanismo, especialmente das Profas. Ana Paula Calvo e Denise Antonucci.

20. O projeto tem como coordenadora a Profa. Pérola Felipette Brocaneli e conta com a parceria do PPGAU FAU-Mackenzie (Profa. Dra. Eunice Helena S. Abascal), com ampla participação dos alunos do Curso de Arquitetura e Urbanismo e dos Profs. dos Cursos de Design, Arquitetura e Urbanismo, Engenharia Civil e Administração da UPM, além dos Profs. e alunos do Ensino Médio do Colégio Claretiano - SP.
Educação Continuada (Prec). O Programa obteve grande visibilidade com a gravação pela TV Mackenzie do evento Arena da Solidariedade, com participação dos Profs. Lucas Fehr e Luiz Benedito C. Telles (in memoriam). Nos dias atuais, outras ações do Escritório Modelo se desenvolvem com a comunidade, por exemplo, atuando na recuperação e requalificação da Praça Capitão Gino Struffaldi, no bairro da Bela Vista, em São Paulo; na elaboração de projeto e montagem de uma brinquedoteca para Casa do Índio (Casai), em São Paulo; e na proposta de transformação de um dos abrigos da entidade Abba. ${ }^{18}$

Semana Viver Metrópole: evento organizado pelo Dafam, e desde 2003, realizado anualmente em outubro, envolvendo todos os alunos e professores durante a Semana de Arquitetura. Com temas diversificados, envolve inúmeras atividades, oficinas e palestras realizadas por convidados reconhecidos no âmbito da Arquitetura e Urbanismo e Design e áreas afins.

Além desses projetos, outros apresentam importantes desdobramentos e envolvem professores e alunos: projeto de pesquisa Design, Videografismo e Efeitos para TV, que promove a integração entre o Curso de Design e a TV Mackenzie, por meio do núcleo de produção MackPro; projeto Comunicação Visual para Regularização Fundiária e Plano de Bairro dos Jardins Piratininga e São Francisco (Penha, São Paulo), que promove a integração entre o Curso de Design e comunidades assentadas em áreas de risco de inundação; ${ }^{19}$ projeto Educação para a Formação da Cidadania Ambiental Urbana: Colégio Claretiano SP, que promove o debate entre alunos e professores do Ensino Médio do Colégio Claretiano e da Graduação e Pós-Graduação da FAU-Mackenzie. ${ }^{20}$

As atividades desenvolvidas pela Empresa Júnior de Design, que acabou de completar dois anos de atividades com pleno sucesso, destacam-se como fundamentais ao protagonismo estudantil, complementando a formação dos futuros profissionais e cidadãos.

Com o intuito de dar suporte à formação complementar dos alunos e amparar tantas ações de Extensão, a FAU-Mackenzie desenvolve o programa Tópicos Especiais em Arquitetura e Urbanismo, que se destaca como importante meio de Ensino, articulado à Pesquisa e à Extensão, e contribui para a formação docente e discente. Tratam-se de componentes curriculares complementares à formação regular oferecida na FAU-Mackenzie, na forma de atividades propostas por professores e pós-graduandos (doutorandos e mestrandos), que podem assumir as modalidades de aulas, visitas guiadas, cursos concentrados, atividades culturais e similares. Tem como propósito colaborar para a formação dos alunos e ampliar a experiência docente dos pós-graduandos - integrando Graduação e Pós-Graduação, e proporcionando experiências de colaboração e integração social. 
Esta importante atividade está definida no Projeto Pedagógico do Curso de Arquitetura de 2013:

\begin{abstract}
"Tópicos especiais" tratam-se de instrumentos totalmente desvinculados de quaisquer programação e conteúdo definidos a priori no curso e, portanto, abertos para serem preenchidos por eventos acadêmicos que contribuam para a complementação dos saberes ligados diretamente à formação profissional, ou de natureza simplesmente cultural. (FACULDADE DE ARQUITETURA, 2013, p. 24-25).
\end{abstract}

O programa Tópicos Especiais apresenta resultados bastante satisfatórios, pois abrange a cada semestre de 10\% a 15\% dos graduandos da FAU-Mackenzie em atividades de extensão acadêmica, com importantes impactos na integração direta com a Pós-Graduação.

Além dos Projetos e Programas de Extensão, a FAU-Mackenzie vem sediando inúmeros workshops e eventos nacionais e internacionais, realizados com o espírito integrador da Graduação à Pós-Graduação, dos quais se pode ressaltar, em 2016, o IV Colóquio Brasil Portugal - Estratégias de Projeto e Intervenção nas Metrópoles Contemporâneas: experiências e perspectivas, evento histórico internacional, organizado pelo PPGAU/FAU-Mackenzie ${ }^{21}$ que abrigou exposição organizada pelo Prof. Roberto Righi, em homenagem ao Prof. Manuel da Costa Lobo, emérito Urbanista português; Desafio Openlab Mobilidade: São Paulo 2030, que explorou cenários de aplicação do transporte na São Paulo de 2030, incluindo carros autômatos - realizado em parceria com o Instituto Cidade e Movimento (IVM) e a Citroen/PSA; ${ }_{i}^{22}$ Palestras Internacionais das Designers Ellen Lupton e Susan Melshop; eventos dedicados à elaboração de protótipos, como o RhinoDay ${ }^{23}$ e Prototype Is Cool24 (Escola de Protótipos) e, ainda, a integração de atividades às Jornadas do Patrimônio, parceria com o DPH/PMSP. ${ }^{25}$

Deve-se ressaltar que as visitas e consequente abertura à integração com instituições, empresas e outras escolas consistem em prática quase diária, distribuídas a cada etapa e a cada ano para os cursos da FAU-Mackenzie. Realizam-se ainda cursos de extensão e de atualização, dos quais se destacam aqueles promovidos em parceria com a Associação Brasileira de Cimento Portland (ABCP); a Associação Brasileira da Construção Metálica (ABCEM); a Associação Brasileira de Distribuidores e Processadores de Vidros Planos (Abravidro); a Associação Brasileira do Alumínio (Abal); e o Instituto do PVC. ${ }^{26}$

\section{Considerações finais}

A última década corresponde a uma nova etapa para a FAU-Mackenzie, decorrente principalmente do incremento qualitativo e quantitativo das atividades de Pesquisa e de Extensão, como fundamentais à formação de profissionais protagonistas e conscientes.
21. O projeto teve como organizador o Prof. José Geraldo Simões Júnior e foi realizado pelo PPGAU em parceria com o Programa de Ciências Sociais da Pontifícia Universidade Católica de São Paulo (PUC-SP), Universidade de Lisboa (Instituto Superior Técnico - IST) e da Universidade Lusófona de Humanidades e Tecnologias. Conta com ampla participação dos docentes do Curso de Design e Arquitetura e Urbanismo, especialmente dos Profs. Angélica Tanus Benatti Alvim e Roberto Righi. O evento foi financiado pelo MackPesquisa.

22. O projeto teve como organizador o Prof. Luís Alexandre Ogawasara e contou com ampla participação dos docentes do Curso de Design, Jornalismo, Engenharia e Arquitetura e Urbanismo, reunindo equipes multidisciplinares que integraram os discentes intercambistas de Nantes com os alunos dos cursos de Design, de Arquitetura e Urbanismo, da Pós-Graduação em Arquitetura e Urbanismo, e de outros cursos da UPM: Computação e Informática Publicidade, Direito, Engenharia Civil e Mecânica. Disponível em: <http:// cidadeemmovimento.org/premiacao-dodesafio-sao-paulo-2030-saiba-como-foicerimonia/> . Acesso em: 15 mar. 2017.

23. Evento Coordenado pelo Prof. Wilson Florio, Coordenador de Pesquisa, e pelo Arquiteto Affonso Orciuoli, da Rede Brasileira de Fabricação Digital (RBFD).

24. Evento Coordenado pelo Prof. Guilherme Michelin.

25. O evento teve como organizadora a Profa. Nadia Somekh e contou com ampla participação dos docentes do Curso, especialmente dos Profs Angélica Tanus Benatti Alvim, Eunice Abascal, José Geraldo Simões Jr. e Carlos Guilherme Mota, fortalecendo a cooperação do Programa de Pós- Graduação (PPGAU UPM) com a PMSP, para sua organização e execução.

26. O Projeto Arquitetura e Construção encontra-se em sua quarta edição e vem sendo coordenado pela Prof. Dra. Maria Augusta Justi Pisani, que envolve vários docentes, alunos da Graduação e da Pós-Graduação. 
Tópico Especial em Fotografia de

Arquitetura e Interiores - ao centro

na foto, Arquiteto Prof. Dr. Rafael

Schimidt com uma turma em frente ao

Centro Histórico e Cultural Mackenzie,

no primeiro semestre de 2015 .

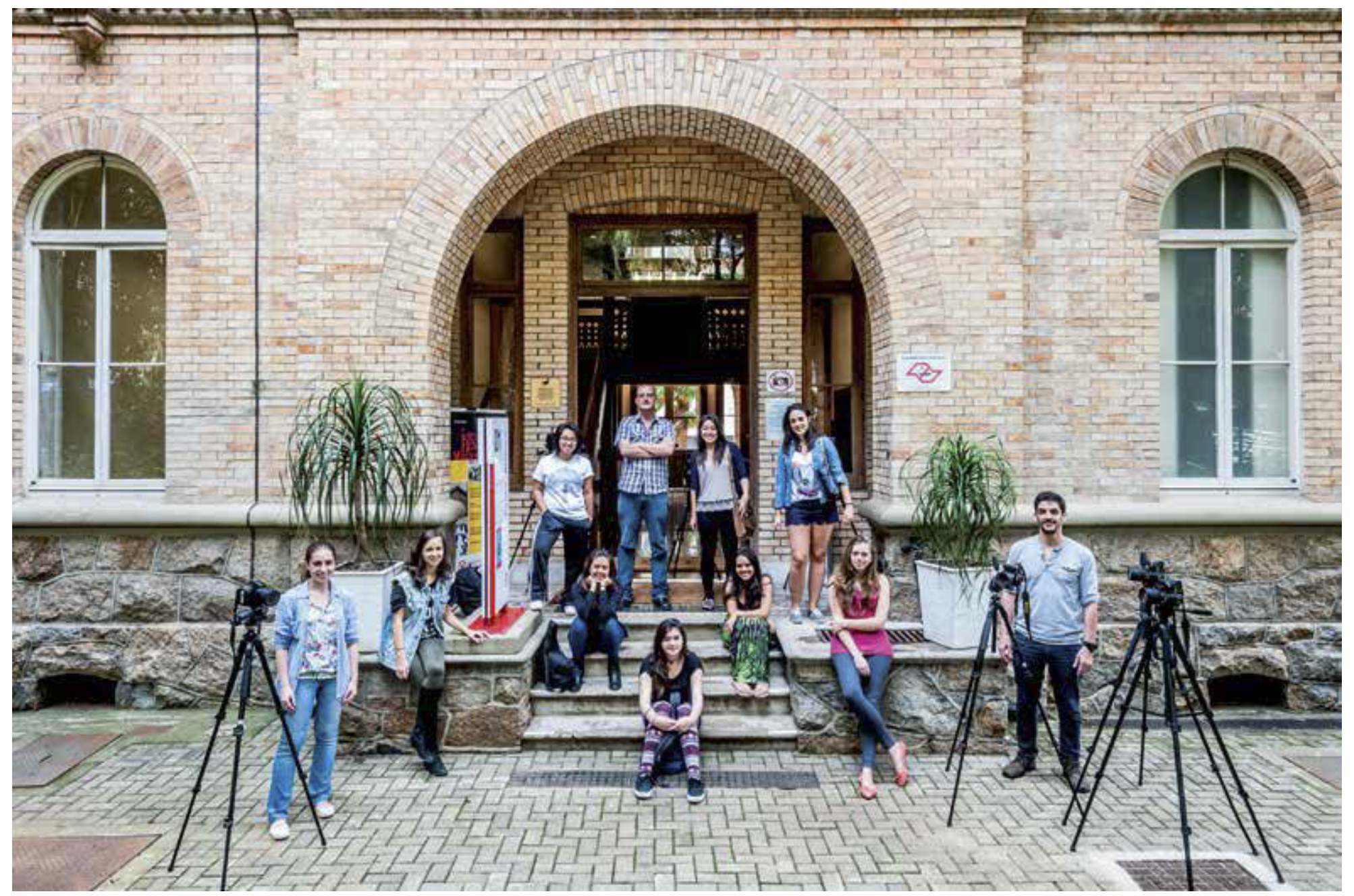


A participação expressiva da FAU-Mackenzie no cenário do ensino e da produção de novos conhecimentos contribui na atualidade para seu posicionamento como uma das mais qualificadas escolas de Arquitetura e Urbanismo e Design do país, alcançando patamares expressivos de Pesquisa e Extensão.

A FAU-Mackenzie tem como princípio educar o ser humano para o exercício consciente e crítico da cidadania, preparando-o para a liderança e contribuindo para o desenvolvimento da sociedade. Com certeza, o tripé Ensino, Pesquisa e Extensão proporciona o fortalecimento dos processos de ensino e aprendizagem no âmbito acadêmico e contribui para a formação de profissionais e cidadãos comprometidos com a construção de sociedades mais justas e inclusivas.

\section{Referências}

ALVIM, A. T. B.; ABASCAL, E. H. S. Fórum de pesquisa em Arquitetura e Urbanismo: percurso e desafios futuros. In: COLÓQUIO DE PESQUISA PROARQ, 3., 2012, Rio de Janeiro. Rio de Janeiro: Proarq: UFRJ, 2012. p. 1-10. v. único.

BRASIL. Constituição da República Federativa do Brasil. 50. ed. Série textos básicos, n. 139 (EPUB). Brasília, DF: Câmara dos Deputados: Edições Câmara, 2016. 610 p.

CALEGARE, M. G. A; SILVA Jr., N. da S. Inter e/ou transdisciplinaridade como condição ao estudo de questões socioambientais. Internacional Interdisciplinar InterThesis, v. 9, n. 2, p. 216-245, 2012. Disponível em: <https://periodicos.ufsc.br/index.php/interthesis/article/ viewFile/18071384.2012v9n2p216/23558> . Acesso em: 21 maio 2017.

CSIKSZENTMIHALYI, M. Creativity: flow and the psychology of discovery and invention. New York: HarperCollins Publishers, 1996.

FACULDADE DE ARQUITETURA E URBANISMO. Projeto Pedagógico da Faculdade de Arquitetura e Urbanismo da Universidade Presbiteriana Mackenzie. São Paulo: FAU-Mackenzie, 2013.

LATOUR, B. Cogitamus: seis cartas sobre as humanidades científicas. São Paulo: Editora 34, 2016. Ciência em ação: como seguir cientistas e engenheiros sociedade afora. 2. ed. São Paulo: Editora Unesp, 2011.

MARQUES, F. O DNA da inovação nas metrópoles. Pesquisa, n. 237, p. 28-32, 2015.

MONTANER, J. M. Depois do movimento moderno. Arquitetura e Arte na segunda metade do século XX. Rio de Janeiro: GG, 2003. 
MoSalco, Escritório Modelo da Faculdade

de Arquitetura Mackenzie, abril de 2017.

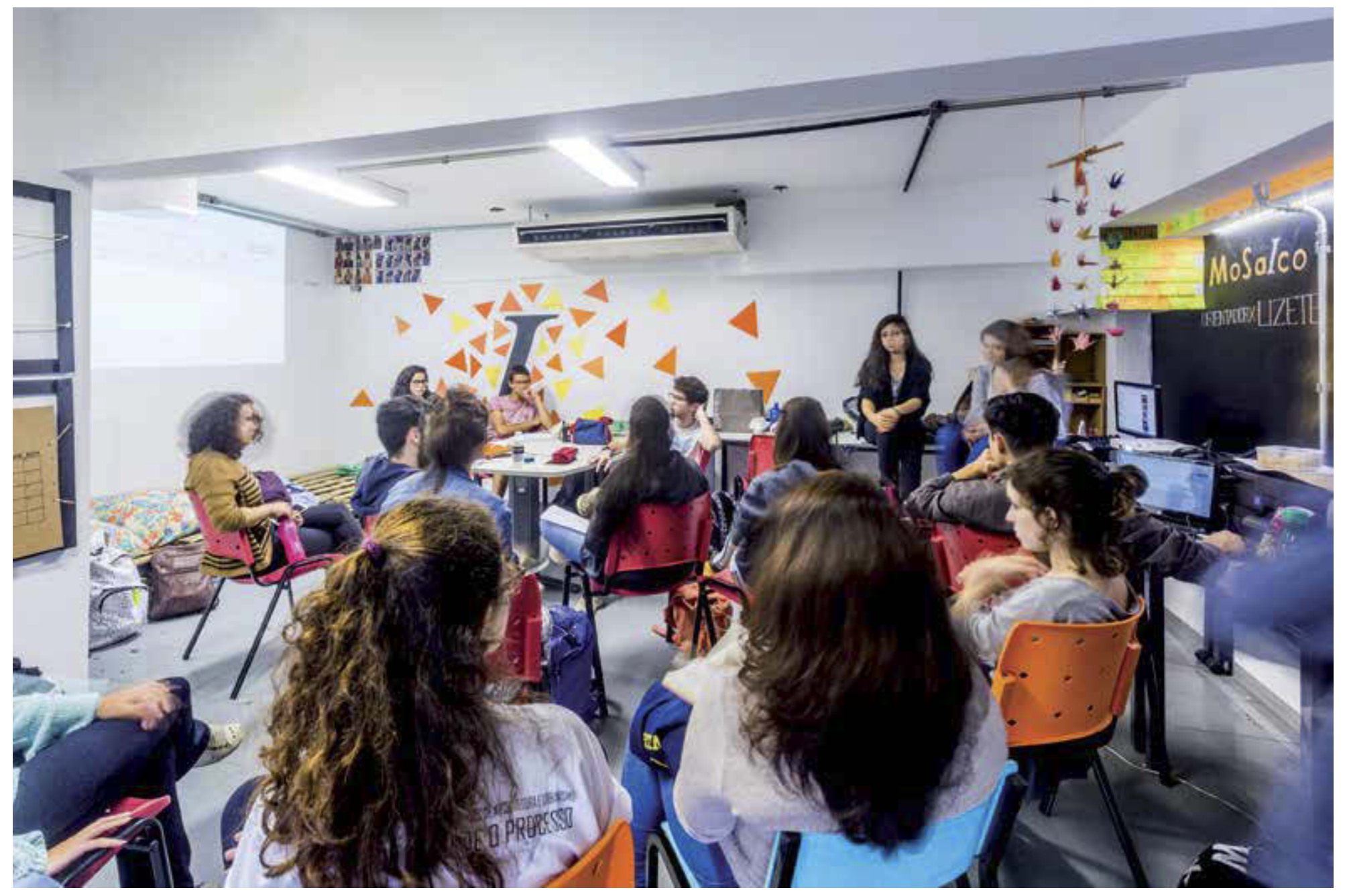




\section{MoSalco: notas sobre o Escritório Modelo da FAU-Mackenzie}

Lizete Maria Rubano, Lucas Fehr

O Escritório Modelo de Arquitetura e Urbanismo (Emau) tem como perspectiva viabilizar, na formação dos estudantes, experiências de cidadania e de construção do pensamento crítico. Apresentar esse objetivo não traduz, entretanto, o que tem sido nossa vivência de discussão, debate, aprendizagem, trabalho conjunto e complementar, enfim, de interesse pela realidade e, essencialmente, de formação, que temos experienciado ao longo desses 13 anos de Emau.

O MoSalco se constituiu com poucos (alunos e professores) em pequeníssimo espaço dentro da Escola. Hoje, habita o terceiro andar e abriga muitos cacos, conquistados - ano a ano - pelo mês de imersão (evento de recepção dos calouros em que o escritório é apresentado de maneira precisa e sedutora).

Com o Emau, identificamos que oferecer aquilo que aprendemos a fazer (projetos, fotos, mobiliário, publicações etc.) pode não só ser muito útil (ou até imprescindível) a quem recebe, mas também tem trazido a cada um de nós, participantes desse mosaico, experiências de força e valor, ambos aplicados no sentido do reconhecimento do papel social do arquiteto e da construção da cidadania, traduzidos em visão de mundo e nosso papel nele.

Aqui, estamos falando da universalização dos direitos, concepção do processo civilizatório que estrutura a motivação do escritório. Estrutura, também, a vontade de aprendermos uns com os outros quanto à ampliação de nossa possibilidade de tangenciar o mundo - do ambiente e das pessoas - para atribuir-lhe uma possível - e desejada - qualidade nova.

O MoSalco tem como perspectiva uma gestão horizontal e coletiva, e assim tem se organizado. Representa importante instrumento de formação, e ali estudantes de todos os períodos do Curso contribuem e trocam suas experiências. Os trabalhos são compactuados com as instâncias da sociedade civil, com as quais estabelece relação de colaboração e parceria. E é ainda dessa maneira que o Emau se organiza internamente.

O forte e estrutural nessa experiência para todos nós - professores e alunos - é o fato de que os trabalhos são motivações de discussão de temas significativos para a realidade de nossas cidades e sociedade, e para que uma ética, de trabalho e de cooperação, seja valorizada em experiência de troca e de prestação de serviço de mão dupla.

O Emau-MoSalco também conforma, como um caco, estrutura maior do movimento estudantil - a Federação Nacional de Estudantes de Arquitetura e Urbanismo do Brasil (FeNEA) e os Conselhos de Entidades Estudantis de Arquitetura e Urbanismo (nacionais e regionais).

Ele tem participado, com intensidade, dos encontros que agregam os escritórios-modelo (Seminário Nacional dos Escritórios Modelos de Arquitetura e Urbanismo, SeNEMAU) e colocado, em debate, nossas experiências coletivas de formação, atuação nos grupos organizados e, essencialmente, de construção de frentes de trabalho fundamentais a diversas demandas sociais. Constitui possibilidade de apresentar, dentro da própria escola - e para a sociedade -, uma alternativa de apoio pelo projeto, entendido amplamente. 


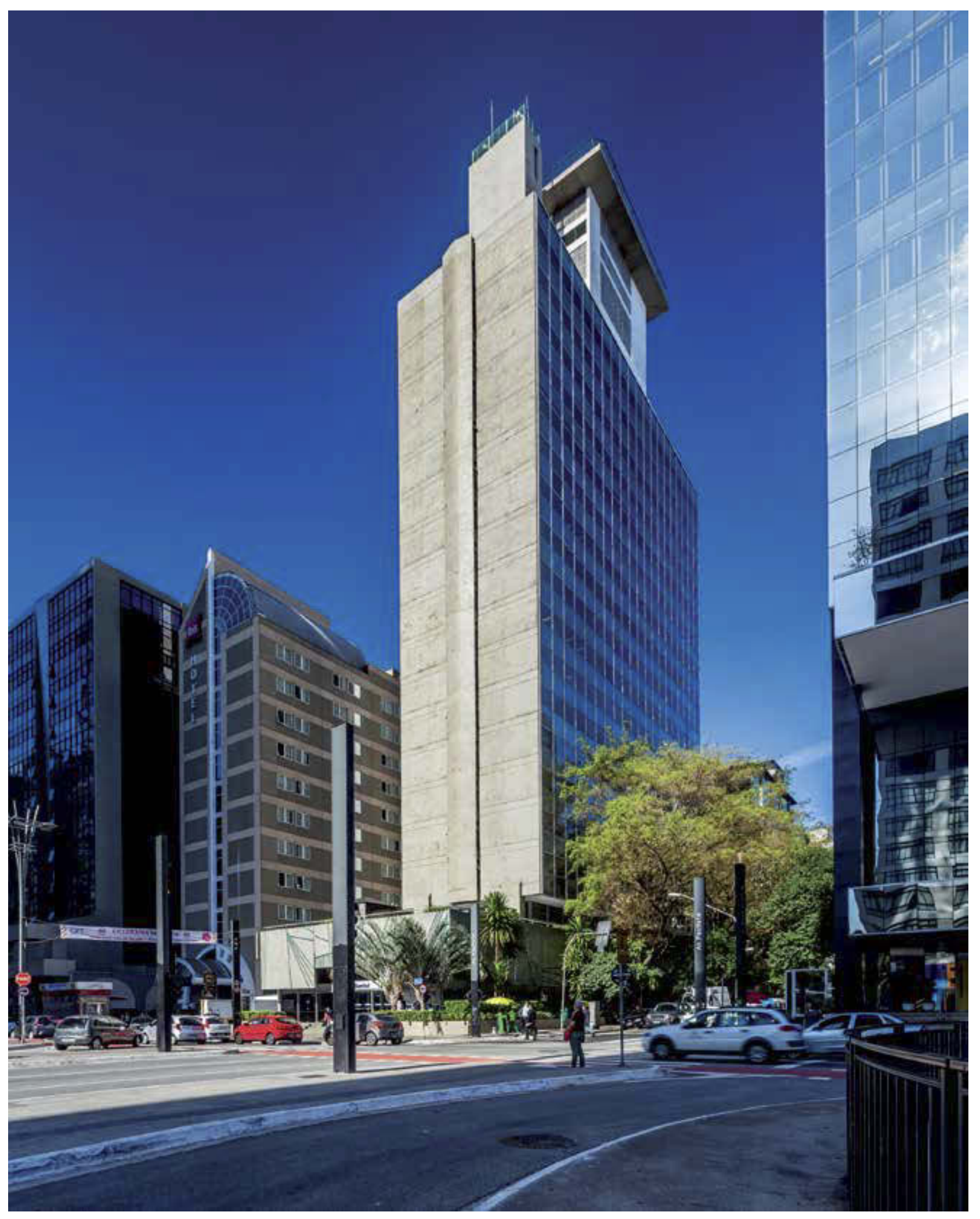


O projeto pode ser um instrumento solidário aos movimentos de resistência urbana, um instrumento emancipatório aos grupos sociais distanciados do acesso e do direito à cidade, de requalificação de equipamentos de uso coletivo e público, de proposta para se viver junto. E é nesse sentido que buscamos atuar no cotidiano da experiência coletiva e nas tarefas postas ao MoSalco que, para além de desafios, representam importante contribuição à formação dos Arquitetos e Urbanistas de nossa escola.

\section{Um caco, dois cacos, três cacos... conformando um mosaico: depoimentos}

"A experiência de formação vai além de uma grade curricular. Ela só é uma base primária do universo de saberes que devemos descobrir. Meu desejo era o de começar a enxergar a cidade real e questionar qual seria o meu papel nela... A partir dessa questão, começamos a ver nossa autonomia como estudantes e a decidir que tipo de profissionais queremos ser, ou não ser, quando sairmos da academia. [...] Cinco anos de MoSalco e carrego comigo um dever de poder transmitir isso para os outros cacos, alunos e professores que irão passar por ali. Pois o Emau é um espaço criado por alunos, transformado por todos aqueles que buscam construir, de alguma forma, um mosaico." - Nathália Conte (aluna do $9^{\circ}$ semestre da FAU-Mackenzie).

"O MoSalco representou uma grande aprendizagem para mim. [...] O projeto que mais me marcou e me transformou foi o da Vila Itororó. Esse projeto me mostrou claramente que o território da cidade é um local de disputa em diversas dimensões. [...] Houve também grande aprendizagem pelas inúmeras trocas que vivenciei junto às famílias que viviam na Vila Itororó, junto aos demais colegas do MoSalco, aos professores e amigos. [...] Se é verdade que eu, como caquinho, ajudei a formar o MoSalco, o MoSalco ajudou a me formar não só como arquiteto e urbanista, mas, sobretudo, como cidadão." - Felipe Moreira (Arquiteto formado pela FAU-Mackenzie em 2009).

"Quando entrei na FAU-Mackenzie não sabia ao certo o que um Arquiteto poderia fazer, e durante as primeiras semanas de aula tentei descobrir tudo que a Faculdade podia oferecer além da sala de aula. Foi quando um pessoal entrou numa das aulas, com os olhinhos brilhando, e perguntou: 'vocês conhecem o mosaico?'. Depois desse dia eu não consegui mais sair do sótão. [...] Durante esse período participei dos Grupos de Trabalho e da organização do Seminário Nacional dos Escritórios Modelos de Arquitetura e Urbanismo 2015 (SeNEMAU). Acredito que todas essas experiências tenham contribuído mais do que qualquer outra coisa para a minha formação acadêmica." - Larissa Cortezani (aluna do $10^{\circ}$ semestre da FAU-Mackenzie).
Na página anterior:

Edifício Jorge Rizkallah Jorge, São Paulo, 1976. Projeto do Arquiteto Sami Bussab (Mackenzie, 1967). Painel em concreto da artista plástica Maria Bonomi. 
Atividades de alunos e professores

na Empresa Junior de Design. Ao

fundo o IVM Brasil (Instituto Cidade

em Movimento), ambos escritórios

funcionam nas dependências da

Universidade, ligados à FAU-Mackenzie,

abril de 2017.

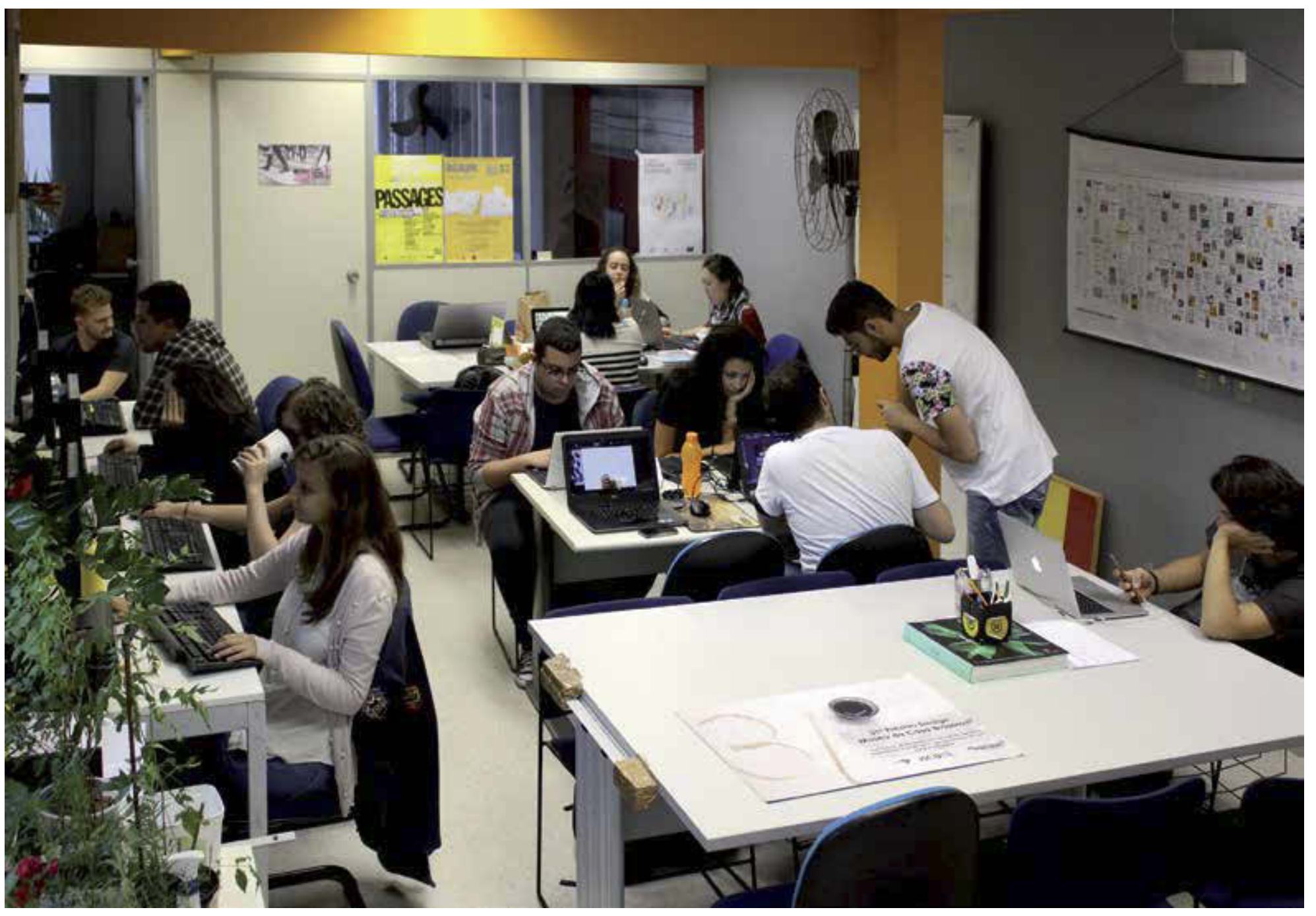




\section{Empresa Júnior de Design Mackenzie}

Kito Castanha, Luís Alexandre F. Ogasawara

O Curso de Design da Universidade Presbiteriana Mackenzie (UPM) vem se modificando durante os tempos, acompanhando a ampliação do campo de atuação profissional e articulando diferentes áreas do saber. O designer, ao desenvolver olhar sistêmico que dê conta da complexidade dos problemas contemporâneos, apresenta-se como profissional transdisciplinar apto a propor soluções às demandas de seu tempo.

Nesse contexto, nasce a Empresa Júnior de Design Mackenzie, fruto da vontade genuína da comunidade da FAU-Design para exercitar os conhecimentos e técnicas aprendidos durante o Curso. Ao atender clientes dos mais diversos setores da sociedade, proporciona a seus membros a possibilidade de adquirir experiência e capacitação profissional ao mesmo tempo que tem papel estratégico para o Curso ao se configurar como espaço privilegiado de extensão universitária.

Por meio de estrutura organizacional bastante atualizada e modelo de gestão alinhado aos mais expressivos escritórios de Design do mercado, a Empresa Júnior de Design Mackenzie consolida a atividade projetual contingenciada pela realidade dos clientes e amparada pela universidade.

Por fim, a Empresa Júnior de Design Mackenzie incrementa a experiência de ensino-aprendizagem e incentiva o desenvolvimento da capacidade empreendedora dos alunos, valorizando seu protagonismo nas relações éticas inerentes à prática do profissional do Design. 
Terminal Rodoviário Tietê, São Paulo,

1977. Projeto dos Arquitetos Renato

Viégas (Mackenzie, 1967) e Roberto

Mac Fadden (Mackenzie, 1967).

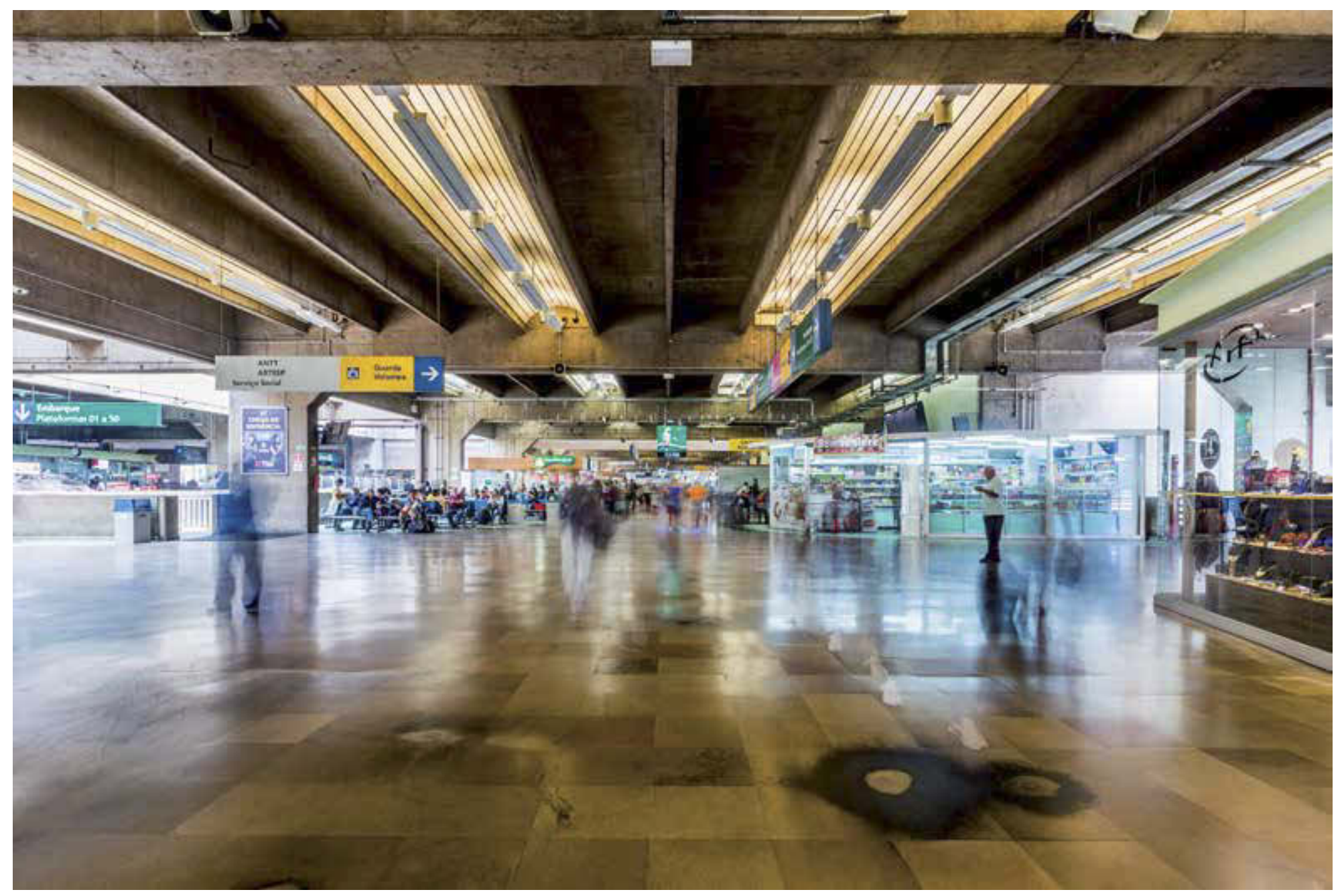

